\title{
Examining childbirth-related trauma and its effect on maternal self-efficacy and appraisal of infant temperament
}

\author{
Teresa B. Stire
}

Follow this and additional works at: https://researchrepository.wvu.edu/etd

\section{Recommended Citation}

Stire, Teresa B., "Examining childbirth-related trauma and its effect on maternal self-efficacy and appraisal of infant temperament" (2014). Graduate Theses, Dissertations, and Problem Reports. 7349.

https://researchrepository.wvu.edu/etd/7349

This Dissertation is protected by copyright and/or related rights. It has been brought to you by the The Research Repository @ WVU with permission from the rights-holder(s). You are free to use this Dissertation in any way that is permitted by the copyright and related rights legislation that applies to your use. For other uses you must obtain permission from the rights-holder(s) directly, unless additional rights are indicated by a Creative Commons license in the record and/ or on the work itself. This Dissertation has been accepted for inclusion in WVU Graduate Theses, Dissertations, and Problem Reports collection by an authorized administrator of The Research Repository @ WVU.

For more information, please contact researchrepository@mail.wvu.edu. 
Examining childbirth-related trauma and its effect on maternal self-efficacy and appraisal of infant temperament

Teresa B. Stire

Dissertation prospectus submitted to the

College of Education and Human Services

at West Virginia University

in partial fulfillment of the requirements

for the degree of

Doctor of Philosophy

In

Counseling Psychology

James Bartee, Ph.D., Chair

Reagan Curtis, Ph.D.

Jeffrey Daniels, Ph.D.

T. Anne Hawkins, Ph.D.

Christine Schimmel, Ed.D.

Department of Counseling, Rehabilitation Counseling, and Counseling Psychology

Morgantown, West Virginia

2014

Keywords: childbirth, trauma, postpartum, PTSD, parental self-efficacy, infant temperament 
UMI Number: 3618146

All rights reserved

INFORMATION TO ALL USERS

The quality of this reproduction is dependent upon the quality of the copy submitted.

In the unlikely event that the author did not send a complete manuscript and there are missing pages, these will be noted. Also, if material had to be removed, a note will indicate the deletion.

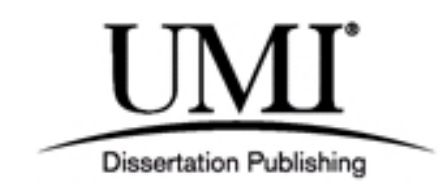

UMI 3618146

Published by ProQuest LLC (2014). Copyright in the Dissertation held by the Author.

Microform Edition () ProQuest LLC.

All rights reserved. This work is protected against unauthorized copying under Title 17, United States Code

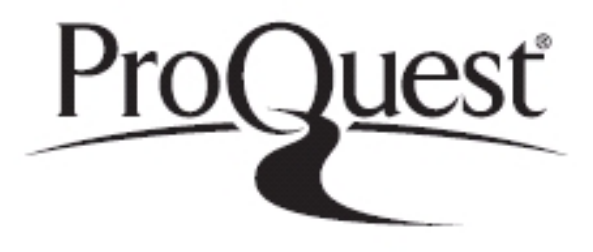

ProQuest LLC.

789 East Eisenhower Parkway

P.O. Box 1346

Ann Arbor, MI 48106 - 1346 


\begin{abstract}
Examining childbirth-related trauma and its effect on maternal self-efficacy and appraisal of infant temperament
\end{abstract}

Teresa B. Stire

It is estimated that $3-9 \%$ of women will meet full diagnostic criteria for posttraumatic stress disorder (PTSD) following childbirth, with another $20-40 \%$ being partially symptomatic for the disorder. While precedents and associated factors leading to childbirth-related PTSD have been fairly well researched, the postpartum outcomes such as the mother's perception of herself in the parenting role, and her appraisal of her infant's temperament have been far less studied. Other psychiatric disorders have been linked to lower estimations of parental self-efficacy and more negative views of infant temperament. This study examined childbirth-related trauma and its effect on maternal self-efficacy as well as mothers' appraisal of infant temperament. The backward stepwise regression model revealed that childbirth-related psychological trauma is a significant predictor of both maternal self-efficacy and appraisal of infant temperament in mothers who are between 3 and 12 months postpartum. 
CHILDBIRTH-RELATED TRAUMA iii

\section{Acknowledgements}

The completion of this project would not have been possible without the support, dedication, guidance, and investment of many people along the way. First, I would like to express my sincerest gratitude to my chair, Dr. James Bartee for being willing to persevere with me on this project over time; his unquestioning commitment was truly a gift for which I am appreciative beyond words. I am thankful for his patience, devotion, wisdom, and insights at numerous points along the way. Additionally, I would like to thank my committee members, Dr. Reagan Curtis and Dr. Jeffrey Daniels who have been a part of this endeavor since its inception. I am thankful to Dr. Curtis for all of his knowledge and oversight of statistical procedures and for having a spirit of openness and helpfulness all along the way. I am thankful to Dr. Daniels for his thorough readings / corrections of my drafts and for helping me to not lose sight of the Disneyrelated rewards I would reap when the project had reached its completion. To Dr. Christine Schimmel I am thankful for her willingness to sign onto my dissertation committee, having never seen my work, and to provide valuable feedback all along the way. I am also especially thankful to Dr. T. Anne Hawkins, both professionally and personally. I am grateful she was willing to participate in this project, and even more grateful for her guidance and mentorship clinically, for her friendship, and for providing a model for me of balancing many different life roles.

Additionally, I would like to thank Vicki Railing for so many things over the span of my doctoral training in general, and this dissertation specifically. Her ever calm and reliable assistance and support were important facets of helping everything run smoothly and fall into place. I am also thankful to Zorrie Georgieva who worked with me on my statistical procedures, assisted in making sense out of things that seemingly didn't, and for sharing in my excitement for statistical significance! Also, to Dr. Al Kasprowicz I am forever appreciative for the role he has played in my life. I am blessed by his belief in me, the hours of supervision he has provided clinically, his genuine interest in and caring about my life as a therapist, and as a person.

Most importantly, I would like to thank my family and friends who provided unending support throughout the years of my doctoral training and dissertation. I am thankful to my dad Danny Buzzard for being my hero, for allowing me the confidence of knowing that he is always in my corner. I am thankful for my sisters and for my in-laws who have also been huge cheerleaders for me over the years. Above all, I am eternally grateful and indebted to my husband and soul mate, Stephen Stire. It was because of his love, sacrifice, support, and unwavering confidence in me over the years that I was able to see this project through to completion. I would not have accomplished this without him. I am thankful for my children Austen, Evan, Caroline, and Aidan for their continued support, tolerance and understanding while I worked on the project. 
Table of Contents

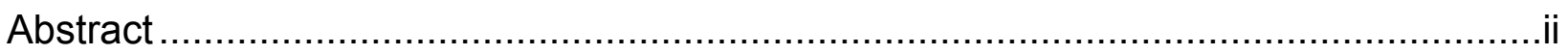

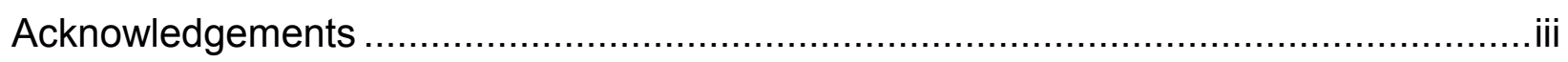

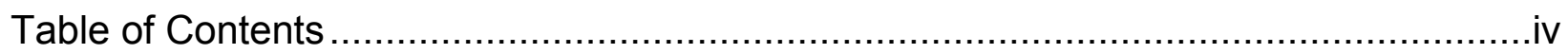

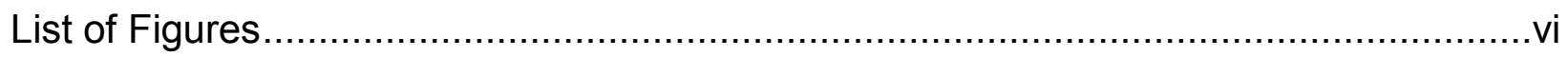

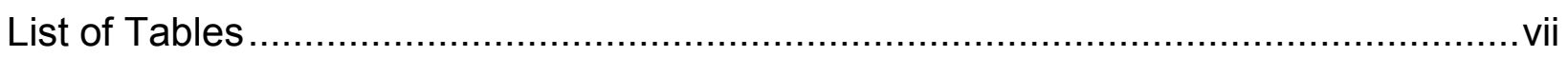

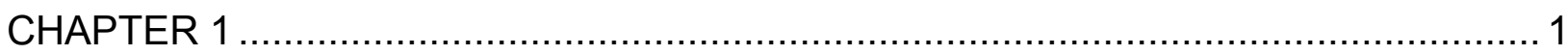

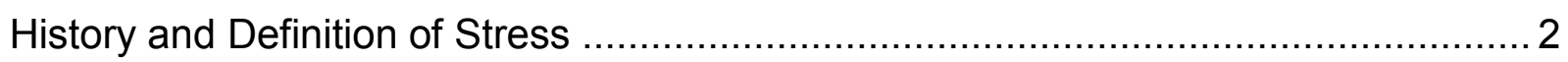

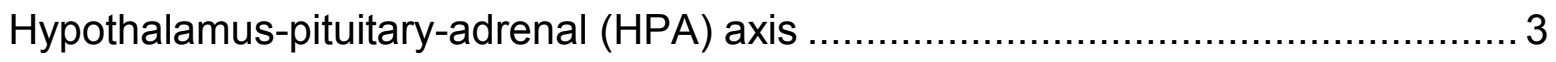

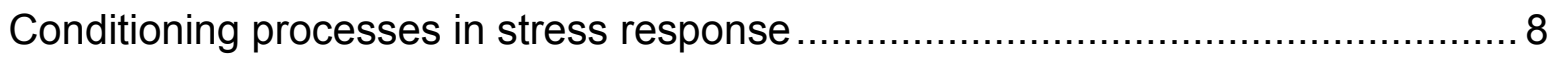

Role of individual perception in definition of stress........................................... 10

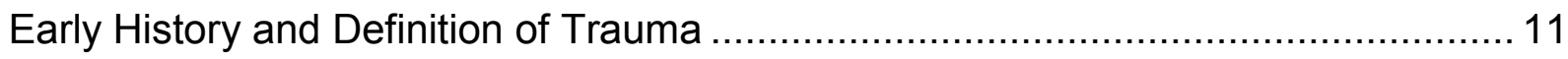

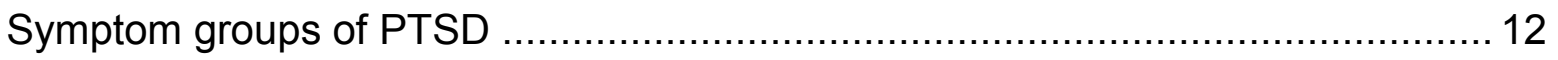

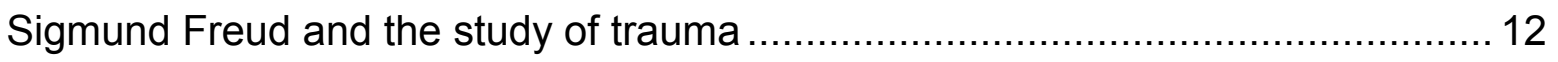

Charcot and Janet's contribution to the study of trauma .................................... 13

Military Combat and Posttraumatic Stress ...................................................... 14

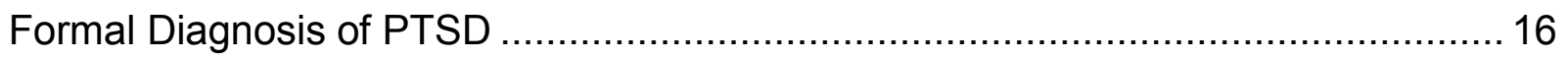

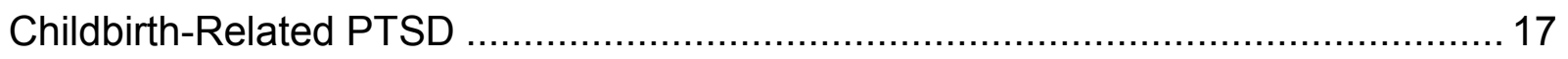

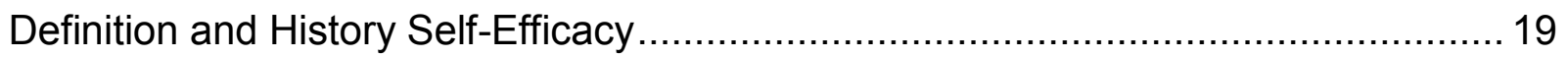

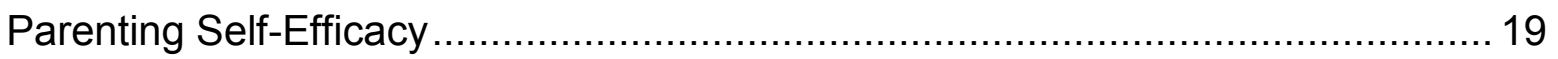

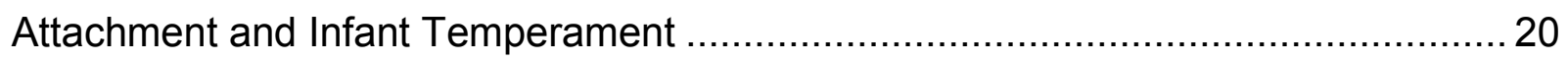

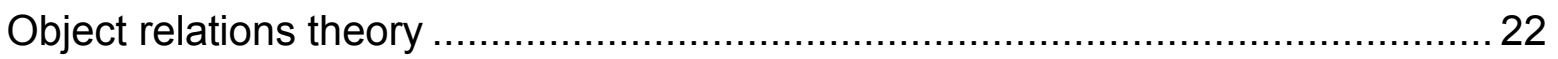

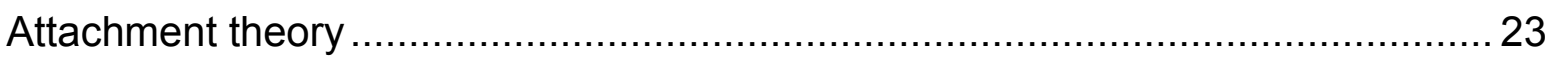

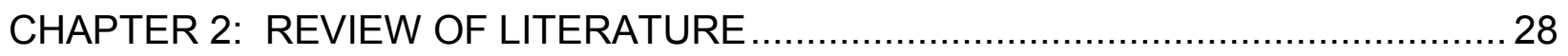

Prevalence and Predictors of Childbirth-Related PTSD......................................... 28

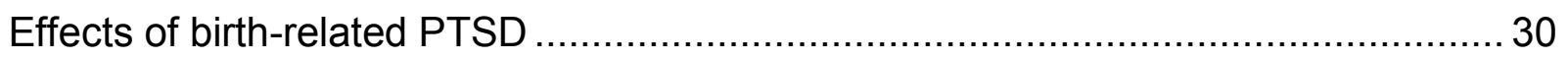

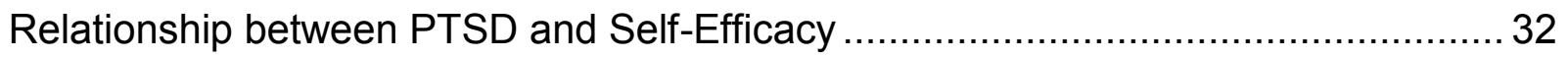

Other Disorders and Effects on Self-Efficacy and Mother-Infant Relationship ........... 33

Factors Related to Mothers' Appraisal of Infant Temperament................................. 35

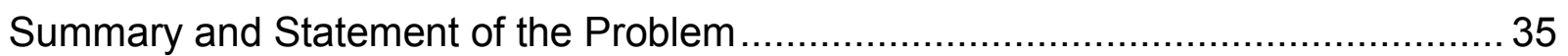

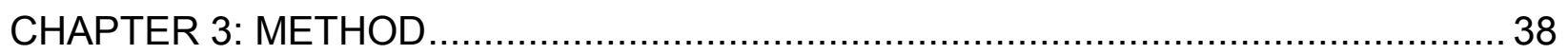

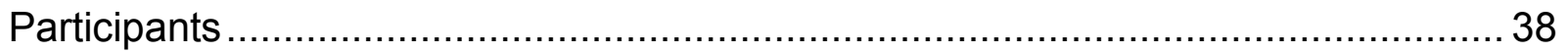

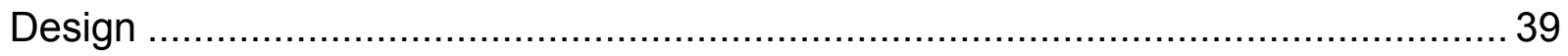

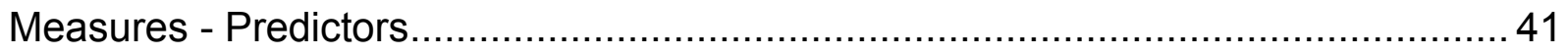




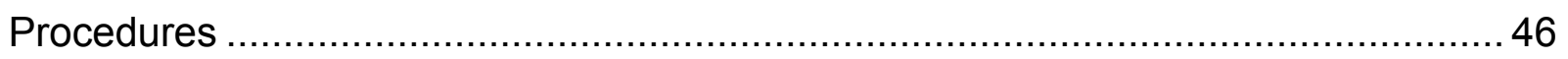

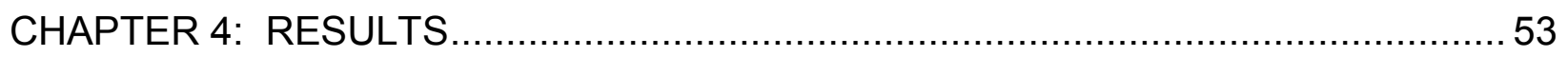

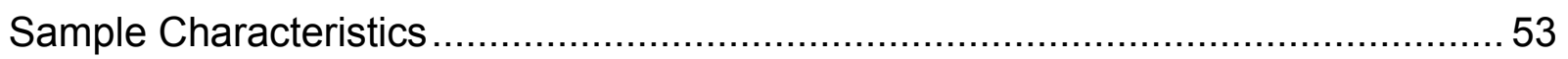

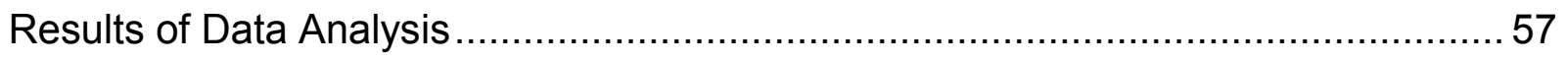

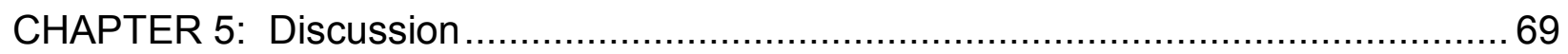

Childbirth-related trauma and parenting self-efficacy........................................... 70

Demographic variables and parenting self-efficacy ............................................ 72

Childbirth-related trauma and appraisal of infant temperament .............................. 74

Demographic variables and appraisal of infant temperament.................................. 75

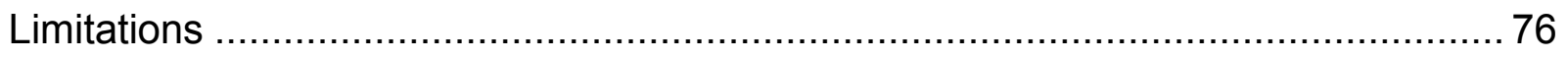

Clinical Implications and Direction for Future Research ..................................... 78

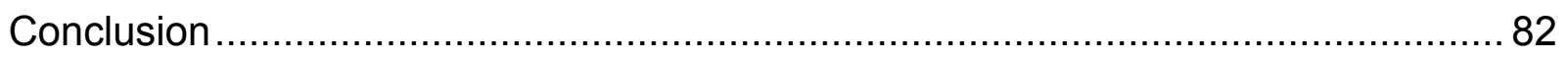

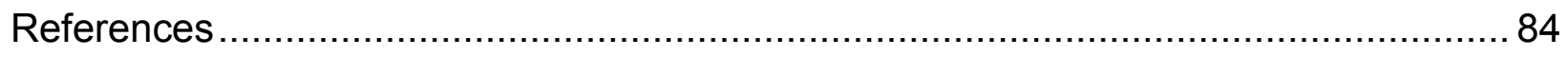

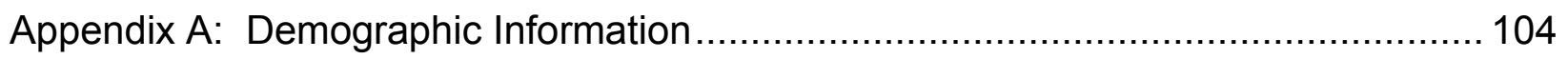

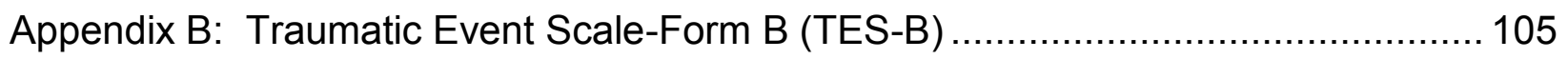

Appendix C: Parenting Sense of Competence Scale ............................................ 107

Appendix D: Infant Behavior Questionnaire-Revised (IBQ-R) ............................... 108

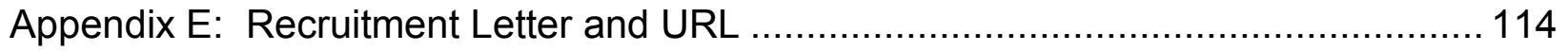

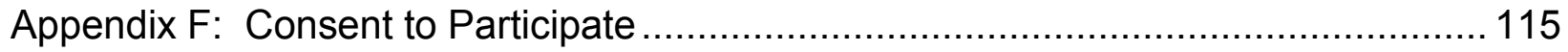

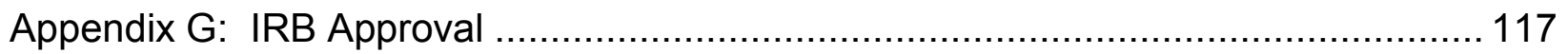

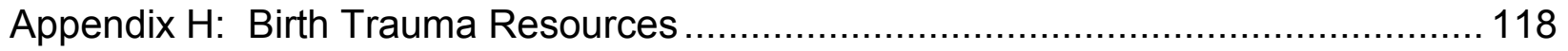

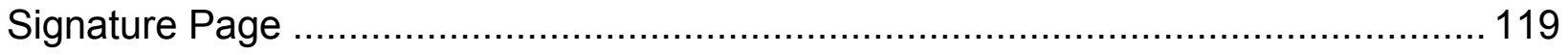




\section{List of Figures}

Figure 1: HPA Axis-Normal Response to Stress

Figure 2: HPA Axis-PTSD Response to Stress

Figure 3: Points of Clinical Intervention 


\section{List of Tables}

Table 1: Demographics of Participants (Categorical) 54

Table 2: Demographics of Participants (Continuous) 55

Table 3: Combined Levels of Categorical Variables 56

Table 4: Descriptive Statistics of Dependent and Independent Variables $\quad 57$

Table 5: Model Summary for Backward Stepwise Regression onto PSOC 59

Table 6: Coefficients of Significant Model PSOC 61

Table 7: Normality Statistics $\quad 62$

Table 8: Model Summary for Backward Stepwise Regression onto IBQ-R 64

Table 9: Coefficients of Significant Model IBQ-R 65

$\begin{array}{ll}\text { Table 10: Normality Statistics } & 67\end{array}$

$\begin{array}{ll}\text { Table 11: Collinearity Statistics } & 68\end{array}$ 


\section{CHAPTER 1}

Traumatic events and their psychological consequences are alarmingly common in our society. Seventy to ninety percent of people will be exposed to a traumatic event at some time in their lives (Ruzek, et al., 2007). According to Kessler, et al. (2005), of those individuals who are exposed to a traumatic event, it is expected that $6.8 \%$ will go on to develop posttraumatic stress disorder (PTSD), which is consistent with the Diagnostic and Statistical Manual - Fourth Edition's (DSM-IV-TR) lifetime prevalence estimate of 1-14\% (American Psychiatric Association, 2000).

"Most early research on trauma and posttraumatic stress disorder (PTSD) focused on male samples" (Vogt, 2007, para.2). This research originates primarily from studies on male veterans of WWI, WWII, and Vietnam. In the years since these studies (post-1980's), researchers have begun to recognize that gender differences in PTSD development and prevalence rates exist. In a meta-analysis of gender differences in posttraumatic stress disorder (PTSD), as well as in examining the relationship between potentially traumatic events (PTEs) and PTSD, Tolin and Foa (2006) found that even though men are more likely to experience a potentially traumatic event, women who experienced a PTE were more likely to meet criteria for PTSD. This has been substantiated in subsequent studies (Crane \& Clements, 2005; Olff, Langeland, Draijer, \& Gersons, 2007; Stuber, Resnick \& Galea, 2006). Olff et al. (2007) concluded that the reason for this is a combination of differences in cognitive appraisal, as well as women's acute reactions to trauma. Women are more likely than men to experience acute psychological and biological responses to trauma including intense fear, avoidance, intrusive thoughts, horror, helplessness, panic, and anxiety (Olff et al., 2007), and 
therefore, are more likely than men to meet diagnostic criteria for the diagnosis. In this study I propose to examine childbirth-related PTSD and its sequelae among women who are between three and twelve months postpartum. This time frame was chosen based on DSM-IV-TR criteria for PTSD diagnosis (symptoms must have lasted for more than a month), as well as taking into consideration the sample for which one of the instruments was normed (parents of infants aged twelve months or younger).

\section{History and Definition of Stress}

Prior to understanding posttraumatic stress disorder as a diagnosis, that which constitutes a stressful or traumatic event will be operationalized. Many attribute the introduction of the concept of stress to Austrian-born endocrinologist Hans Selyë, who was one of the most prolific writers on the topic of stress. He first became interested in studying stress as a medical student in the 1920s, looking into why ill people looked and appeared ill (Jones \& Bright, 2001). Selyë came to view stress in physiological terms as the non-specific response of the body to any demand made upon it (Selyë, 1993). In one of Selyë's seminal works, published in 1936, he described a syndrome produced by 'diverse nocuous agents,' and continued work on this concept for nearly 50 years after this first publication. (Selyë, 1936). Selyë's general adaptation syndrome (GAS) describes three distinct stages: the alarm reaction, the stage of resistance and the stage of exhaustion. In describing the first stage of GAS, Selyë wrote "Experiments on rats show that if the organism is severely damaged by acute non-specific nocuous agents such as exposure to cold, a typical syndrome appears, the symptoms of which are independent of the nature of the damaging agent." (Selyë, 1936, p.32). Selyë observed that this first stage appeared 6-48 hours after initial injury and involved a 
complex set of physiological processes. The second stage of GAS occurred around the 48 hour mark post injury and was reflected in a loss of function of key hormoneproducing systems and organs. Selyë explained that if the insult or injury continued at a relatively low rate, it would result in resistance being built up in this second stage; however, if the insult continued at the same high rate, animals would lose that and enter the third phase, exhaustion, with symptoms similar to those that were seen in the first stage of GAS.

\section{Hypothalamus-pituitary-adrenal (HPA) axis}

The stress response described in Selyë's GAS consists of a number of physiological adaptations and processes, the most prominent of which is an activation of the hypothalamus-pituitary-adrenal (HPA) axis. When a potentially threatening or aversive system is encountered, emotional responses are generated in the limbic system, an evolutionarily old area of the brain responsible for survival-related behaviors, such as sexual reproduction, fear, and aggression. The limbic system can then activate an area of the brain known as the hypothalamus. Hypothalamic neurons send releasing factors to the anterior pituitary gland, which releases specific arousal hormones. These hormones stimulate the adrenal cortex, which in turn secretes corticosteroids, longer acting agents, into the blood (particularly cortisol in human beings). With the release of cortisol and other corticosteroids, the metabolism is activated, blood sugar is elevated, and the body is readied for action. This phenomenon is sometimes referred to as the 'fight-or-flight' response. Like other endocrine systems, all of which are feedback regulated, the HPA axis is efficient in regulating the output systems under its control. One of the hormones released by the hypothalamus, corticotropin-releasing hormone 
$(\mathrm{CRH})$, stimulates production of anterior pituitary adrenocorticotropic hormone (ACTH). ACTH affects the adrenal cortex and regulates cortisol secretion, which in turn affects numerous other organ systems. As stress rises (as evidenced by increased secretion from the adrenal medulla of norepinephrine and epinephrine), feedback loops to the hypothalamus direct the anterior pituitary to respond accordingly. The hypothalamus can be considered a final common pathway by which signals from multiple systems reach the anterior pituitary.

After the initial alarm reaction a negative feedback loop is engaged, whereby the adrenal corticosteroid cortisol inhibits further production of itself, shutting down the initial phase of the stress reaction, and moving the body into the second phase (Figure 1).

The HPA axis is important to the field of trauma because it seems as though in individuals with PTSD, it appears that something is amiss within this process. Rachel Yehuda (Yehuda et al., 1990) pioneered the discovery that in those individuals with PTSD, there is not enough cortisol released from the zona fasciculata, in the second layer of the adrenal cortex, to initiate the negative feedback loop and halt the alarm reaction (Figure 2).

The presence of low cortisol levels in trauma survivors has been intriguing because it is counterintuitive to the idea that stress would be associated with high cortisol levels.

In the case of major depressive disorder (MDD), generalized anxiety disorder (GAD), and general stress theory, stressors that result in the activation of CRF release from the hypothalamus also result in elevated cortisol levels, whereas lower levels of cortisol are thought to result directly from a cessation of activation 
by CRF. Thus one paradox in PTSD, clearly a disorder in which exposure to stress is a critical feature, is the presence of low cortisol levels. (Yehuda, 2002, p.33).

It has been hypothesized that this deficit in cortisol may be a manifestation of a more primary alteration—an enhanced negative feedback inhibition resulting from increased glucocorticoid receptor sensitivity. There are opposing viewpoints in current research on the role which GCs play in stress response.

One view posits that GCs help mediate the ongoing or pending stress response, either via basal levels of GCs permitting other facets of the stress response to emerge efficaciously, and/or by stress levels of GCs actively stimulating the stress response. In contrast, a revisionist viewpoint posits that GCs suppress the stress response, preventing it from being pathologically overactivated. (Sapolksy et al., 2000, p.55).

Another possible pathway to explain why cortisol levels are low despite repeated exposure to stressors that cause a rise in CRF levels is related to an individual's prior stress history.

PTSD represents a situation where there has been a failure of restitution of the body to its pre-stress baseline. The biological findings appear to mirror this phenomenon; there may be biological risk factors that determine the responses that are most likely to result in a PTSD syndrome. These biological risk factors could be related to the prior stress history of the person experiencing a traumatic 
event (Yehuda, 2002, p.33).

\section{Hypothalamic-pituitary-adrenal (HPA) axis}

\section{Normal Response to Threat}

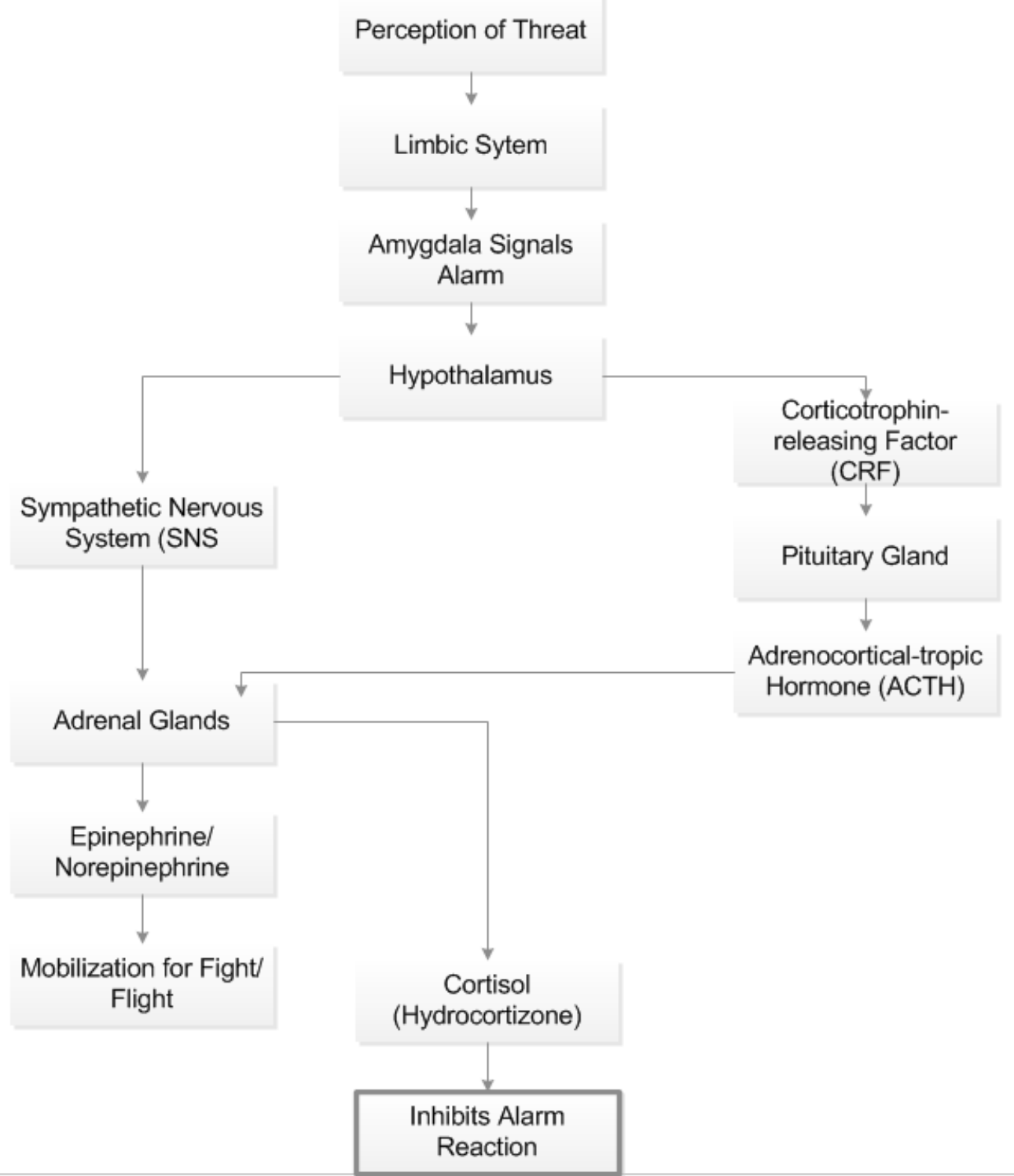

Figure 1. This diagram illustrates the neurological processes which take place during the normal human stress response. (Rothschild, 2000) 


\section{Hypothalamic-pituitary-adrenal (HPA) axis}

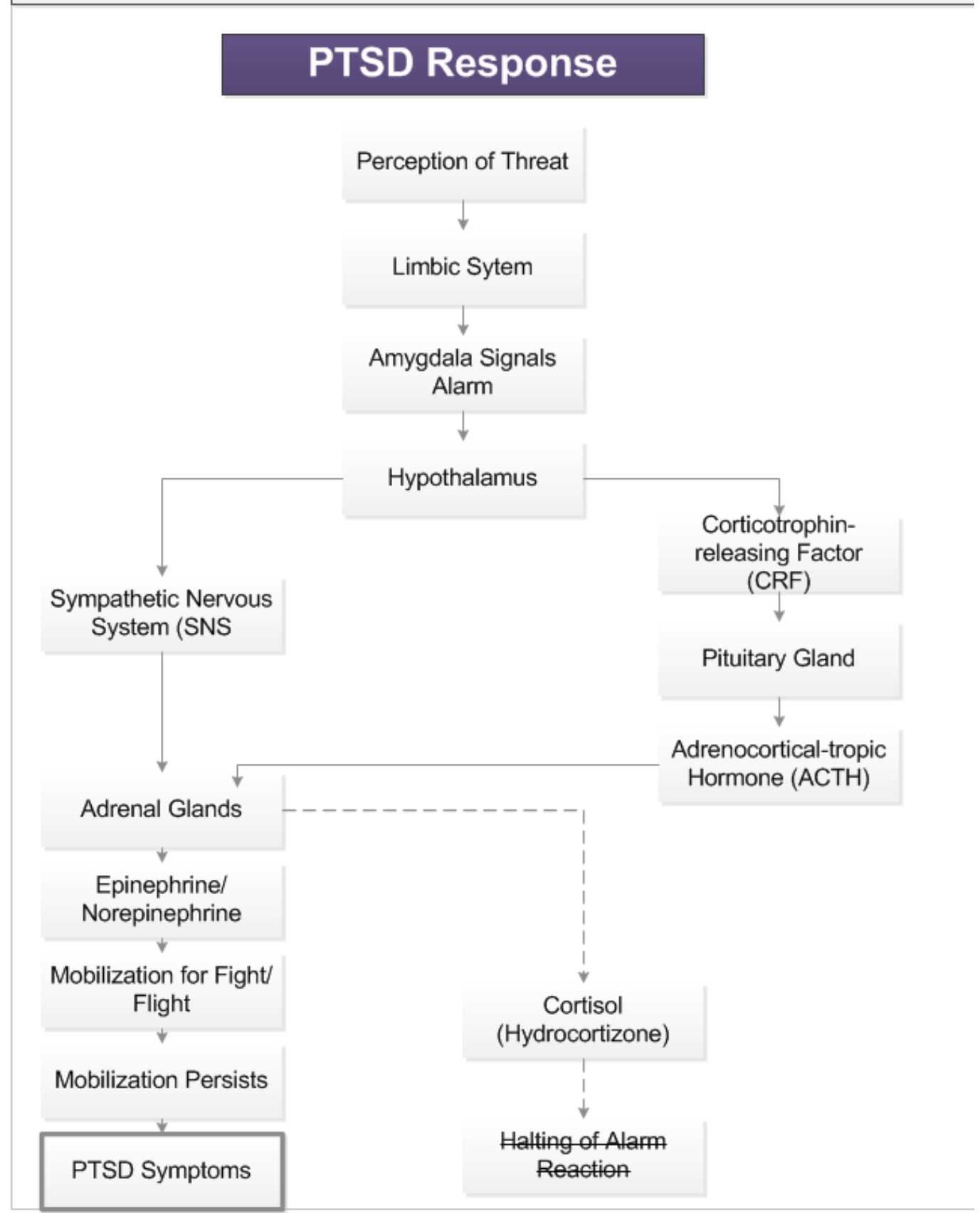

Figure 2. This diagram illustrates the neurological processes thought to have been taking place in individuals with PTSD. (Rothschild, 2000) 
While this process of HPA activation is relatively well understood, the role of stressor(s) that trigger the activation of the HPA axis are less clear. Selyë's studies focused solely on the application of physical stressors, wherein the definition of a psychological stressor is far less straightforward. One working definition of a psychological stressor could be "a situation that elicits behaviors, such as escape or aggression, likely to terminate the situation: in other words, aversively motivated behaviors subserve homeostatic functions." (Stanford \& Salmon,1993, p. 90). The difficulty with this and other similar definitions is that in some instances it has been observed that obvious putatively stressful situations can fail to activate the HPA axis, whereas there are situations that cause an activation of the HPA axis, which are neither observed to be stressful nor are they reported to be subjectively stressful.

\section{Conditioning processes in stress response}

From this, it is often inferred that a complex system of conditioning takes place, rendering some situations and events as being perceived as stressful by one individual and not another. Conditioning is an active and ongoing process, which changes across time, exposure, and contingency patterns.

Classical conditioning. The concept of classical conditioning was first introduced by Russian physiologist Ivan Pavlov (Pavlov, 1927). The theory posits that, if an initially neutral stimulus (labeled as the conditioned stimulus or CS) was presented at about the same time as the unconditioned stimulus (UCS), then this neutral stimulus would take over some of the powers in eliciting the previously unconditioned response (UCR), which subsequently became known as the conditioned response (CR).

Classical conditioning is especially pertinent to the discussion of PTSD because a great 
deal of knowledge has been attained about the neuronal basis of conditioned learning, which may figure into the mediation of, and habituation to stressors. The amygdala, an almond shaped mass of nuclei located deep within the temporal lobe of the brain, serves as the neuroanatomical hub for Pavlovian fear conditioning. Pathways that carry information about signals for biologically important events arrive in the amygdala, inducing pre- and postsynaptic neuronal changes there. This neural plasticity is the physical basis of associative memory formation. The basolateral amygdala (BLA) appears to play a critical role in the acquisition phase of extinction. The BLA is composed of several anatomically and functionally distinct nuclei, including the lateral (LA) and basal (BA) nuclei. The LA is known to be a critical site of synaptic plasticity during fear learning (Davis, 2000; Maren, 2001; Maren \& Quirk, 2004). In summation, classical learning appears to be mediated by a distributed network of brain areas centered around activity in the BA, also recruiting other circuits and brain areas. Stress elicits structural changes in key areas implicated in extinction, such as the medial prefrontal cortex (Holmes \& Wellman, 2009), amygdala (Vyas et al., 2002), and hippocampus (Roozendaal et al., 2009). In the instance of HPA activation in response to a stressor, the idea could explain why some seemingly non-stressful events or circumstances could activate the HPA axis in certain individuals, if they had previously been strongly paired in the individual's mind with a stressful event. The pairing would have brought about functional changes, which consequently led to structural changes resultant from the increased activity of certain synaptic circuits. This process whereby there is a persistent increase in the synaptic strength is referred to as long-term potentiation (Cooke \& Bliss, 2006). 
Operant conditioning. Also of importance in examining human response to stress and trauma is the role of operant conditioning, credited primarily to behaviorist B.F. Skinner. Skinner proposed that behavior would increase or decrease based upon the consequences of the behavior. Operant conditioning theory is especially relevant to understanding the processes that maintain posttraumatic stress disorder. Specifically, avoidant behavior reduces the anxiety associated with the stressor, thus serving as a negative reinforcer. However, at the same time, the avoidance maintains the originally learned anxiety associations, because it prohibits exposure and extinction of the conditioned responses which arose from the original anxiety producing stimulus (Skinner, 1938/1971).

\section{Role of individual perception in definition of stress}

Taking into account the role that conditioning plays, Lazarus and Folkman defined stress as "a relationship between the person and the environment that is appraised by the person as taxing or exceeding his or her resources and endangering his or her well-being" (1984, p.569). The emphasis in this definition is shifted from the relationship between objective stressors to the process whereby the individual views a situation as being stressful. It is more fluid and takes into account all variables in the environment at the time.

An individual's appraisal of a stressful event plays a significant role in affective processing of the stressful event. Coping strategies, which represent behavioral and cognitive efforts to deal with stressful encounters (Lazarus \& Folkman, 1984; Terry, 1994), can be separated into two categories: problem-focused or emotion-focused (Folkman \& Moskowitz, 2000). These two categories define the function of coping as 
dealing with the problem or with its emotional and physiological outcomes. Individuals who employ problem-focused coping tend to be more effective at neutralizing emotional responses to stress than those who rely more on emotion-focused coping (Elwood et al., 2009; Folkman \& Moskowitz, 2000). Cognitive appraisal and coping strategies are considered to be reliable predictors into the development of posttraumatic stress; studies have demonstrated that emotion-focused coping strategies are correlated with a higher incidence of PTSD (Kanninen, Puinamki, \& Qouta, 2002; Rubin, Bernstein, \& Bohni, 2008). Research has also shown that stressors which are perceived as uncontrollable, novel, challenging, or threatening contribute to the stress response and that specific cognitive appraisals produce certain emotional responses (Dickerson \& Kemeny, 2004; Lazarus \& Folkman, 1984; Tomaka, Blascovich, Kelsey, \& Leitten, 1993).

\section{Early History and Definition of Trauma}

The DSM-IV-TR (2000) diagnosis of PTSD divides symptoms into three groups:

(1) Re-experiencing of the traumatic event, which can take the form of intrusions, dreams, and re-experiencing the emotions associated with the trauma; (2) Avoidance of stimuli associated with the trauma and numbing emotional responsiveness, including avoiding thoughts and feelings about the trauma, avoiding activities associated with the trauma, and emotional changes such as detachment from others; and (3) Symptoms of hyper arousal, including difficulty sleeping and/or concentrating, irritability and excessive startle responses. Each of these symptom groups is clearly connected to the physiological components and conditioned learning concepts described previously. 


\section{Symptom groups of PTSD}

Re-experiencing of traumatic event. When considering the first symptom group from the standpoint of classical conditioning, the traumatic event (US) may have, in the individual's mind, been paired with an array of otherwise non-related stimuli (CS), the individual begins to re-experience the response associated with the trauma when presented with these other stimuli (CR).

Avoidance of stimuli. The second symptom group can best be understood considering the tenets of operant conditioning, whereby the avoidance of thoughts, feelings, and situations associated with the trauma serves as a negative reinforcer, at least in the short-term, with the individual believing that s/he has successfully extinguished the presence of the trauma response.

Hyperarousal. With the third group of symptoms, the individual continues to experience symptoms of the "alarm reaction" within the body due to the deficit in the release of cortisol as described above, thus placing the body in a state of hyperalertness.

\section{Sigmund Freud and the study of trauma}

The concept of trauma and traumatic stress dates back to the work of Sigmund Freud, Austrian neurologist and "father of psychoanalysis" and his work with patients diagnosed with hysteria. In his treatment of hysteria, Freud made a clear connection between hysteria and "war" neuroses, noting that the common element in both was fear. Freud and his colleague, Josef Breuer explained "any experience which calls up distressing affects—such as fright, anxiety, shame or physical pain—may operate as a trauma" (Freud \& Breuer, 1895/1961, p.6). Freud's ideas about trauma developed 
gradually over the course of his career. In 1917, Freud wrote "We apply it to an experience which within a short period of time presents the mind with an increase of stimulus too powerful to be dealt with or worked off in the normal way...resulting in permanent disturbances of the manner in which the energy operates" (Freud, 1895/1961, p.275). Freud was the first to introduce the concept of dissociation as early as 1893 , which he termed "a splitting of the mind." He described situations where there appeared to be an overuse of dissociation to the point in which it became the individual's primary psychological defense (Freud, 1895/1961).

Freud's pioneering approach to individuals [who had experienced a traumatic event] involved retelling the traumatic event in order to promote emotional catharsis and abreaction. This approach can be seen as a precursor to current cognitive-behavioral therapy (CBT), especially prolonged exposure techniques. (Friedman, et al., 2007, p.37)

\section{Charcot and Janet's contribution to the study of trauma}

Around the same time, Jean-Martin Charcot, often considered to be "the father of neurology", was beginning to broaden the understanding of trauma.

Until Charcot, the common treatment for hysteria was hysterectomy. Charcot was the first to understand that the origin of hysterical symptoms was not physiological but rather psychological in nature, although he was not interested in the inner lives of his female patients. He noted that traumatic events could induce a hypnotic state in his patients and was the first to describe both the problems of suggestibility in these patients, and the fact that hysterical attacks are 
dissociative problems—-the results of having endured unbearable experiences. (van der Kolk, Weisaeth, \& van der Hart, 1996, p. 50)

One of Charcot's students, Pierre Janet, a French physician, psychotherapist and hypnotist, was also instrumental in bringing a psychological approach to posttraumatic reactions. Janet introduced a "phobia of memory," a foreshadowing of what is now termed PTSD. Janet was very much aware of the need to create a safe, stable patienttherapist relationship before attempting to deal with trauma. He considered "rapport," or what would be known today as therapeutic alliance, between patient and therapist indispensable for resolution of the trauma. Janet also believed that moral guidance was an essential element of the doctor-patient relationship at all stages of treatment (Janet, 1897). Janet's treatment of trauma continues to serve as the basis for many trauma treatment protocols in use today. Janet's psychotherapeutic approach to posttraumatic stress consisted of the following stages: (1) Stabilization, symptom-oriented treatment and preparation for liquidation of traumatic memories, (2) Identification, exploration and modification of traumatic memories, and (3) Relapse prevention, relief of residual ,

\section{Military Combat and Posttraumatic Stress}

An influential event in study and treatment of trauma was the start of World War I. During World War I, military combat formed a major background in which posttraumatic stress was beginning to be studied. During World War I, Charles Myers first wrote about the concept of "shell shock" which was used to describe soldiers who were involuntarily shivering, crying, fearful, and had constant intrusions of memory (Myers, 1915). Initially, it was thought to have been purely organic, having something to do with interrupted circuitry within the brain. 
In his seminal works, Traumatic Neuroses of War and War Stress and Neurotic Illness (Kardiner, 1941; Kardiner \& Spiegel, 1947), Abram Kardiner, was among the first to identify behavioral and cognitive disturbances that occur as a result of traumatization, and was the first person to formally integrate organic and psychological explanations for posttraumatic stress response.

In describing the traumatized World War I veterans he treated, Kardiner documented these patients' tendency to be triggered by sensory stimuli and to act out as if they were still involved in military combat. He characterized them as having flashbacks and panic attacks evoked by situations reminiscent of their traumatic experiences. Kardiner also suggested that these patients often failed to make conscious connections between their emotional states and their prior traumatic experience. These observations lead back to the classical fear conditioning conceptualization of traumatic stimuli and responses. (Friedman, et al., 2007, p. 39)

The concept of posttraumatic stress continued to be examined throughout World War II, as military officials began pre-screening techniques to predict those who would be vulnerable to war-related neuroses. Despite the extensive use of psychiatric selection criteria which screened out over one million soldiers for psychological reasons, (Marlowe, 2000), there continued to be staggering numbers of psychiatric casualties in war. In fact, "so many soldiers were affected that psychiatrists were confronted with the reality that psychological weakness had little to do with subsequent distress in combat. Thus, terminology changed from 'combat neurosis' to 'combat exhaustion,' or 'battle fatigue'" (Bentley, 2005, p. 26). 
Along with the development of supportive interventions for "combat fatigue," World War II also brought about the need to consider the effects of trauma on victims of trauma, other than combat. Studies on Holocaust survivors (Krystal, 1968) and Hiroshima (Lifton, 1967) further demonstrated the effects and symptomatology of enduring traumatic events. Krystal (1988), from this work, developed an informationprocessing model of psychological trauma, which included the idea that these traumatic events can disrupt an individual's ability to function, often resulting in alexithymia, a profound disconnect between words and feelings. "Once this system is disrupted, anxiety and other affects fail to serve psychic needs. Affect may become muted, overwhelming, or inappropriate" (Foa, et al., 2000, p. 180).

\section{Formal Diagnosis of PTSD}

A formal diagnosis of PTSD was first listed in the third edition of the Diagnostic and Statistical Manual of Mental Disorders (DSM-III) (American Psychiatric Association, 1980). As detailed below, while trauma symptoms have been studied for a number of years, it has been quite recently that it has become accepted that women can develop posttraumatic stress disorder following a difficult birth. In 1994, the DSM-IV included a revised definition of what constitutes a traumatic event (American Psychiatric Association, 1994). A traumatic event is seen as an event in which the person witnessed or confronted serious physical threat or injury to themselves or others and in which the person responds with feelings of fear, helplessness, or horror (APA, p.468). In the previous edition of the DSM, the traumatic event had been defined as something outside of the range of usual human experience, leading to confusion among clinicians 
and researchers as to whether childbirth could be seen as an appropriate stressor to make the diagnosis.

\section{Childbirth-Related PTSD}

Based upon research spanning the last decade and a half, it is now widely accepted that childbirth can qualifiy as a traumatic stressor (Ayers \& Pickering, 2001; Bailham \& Joseph, 2003; Beck, 2004; Czarnocka \& Slade, 2000; Lyons, 1998; Wijma, Soderquist \& Wimja, 1997; Verrault, et al., 2012). Cross-cultural comparisons suggest similar prevalence rates in Europe (i.e. Sweden, Italy, and The Netherlands), the UK, North America, and Australia (Ayers, et al., 2008). Overall, researchers in the field estimate that $3-9 \%$ of women will experience the full DSM-IV criteria for PTSD at some point after giving birth (Olde, et al., 2006; Ayers, 2004; \& Ayers, et al., 2008), with an additional $20-40 \%$ being partially symptomatic, depending on the definition or cut-off endorsed by the particular study, and a full $30-50 \%$ of women reporting that the childbirth experience was traumatic (Ayers, et al., 2008). A recent Australian study sampled 933 women, accurately controlling for possibly confounding psychiatric history (full and partial PTSD from previous trauma, depression, and anxiety), and found PTSD prevalence to be $3.1 \%$ at both 12 and 24 weeks postpartum, while uncontrolled for psychiatric history, the prevalence rates were $6.3 \%$ and $5.8 \%$, respectively (Alcorn, 2010). In a Canadian study (Verreault, et al., 2012) of 308 women, incidence rates of full and partial PTSD were found to be $7.6 \%$ and $16.6 \%$, respectively. Soet et. al (2003) found that the childbirth experience was reported as traumatic by $34 \%$ of participants in a U.S.-based study. 
Overall, the literature continues to be largely focused on prevalence and risk factors while research into management and care remains scarce (Lapp, et al., 2010). Research is also lacking in the area of examining the effects of childbirth-related PTSD on the childbearing woman and her role as mother. The studies which have been done in this area have concluded that childbirth-related PTSD has had influence on a woman's physical well-being, mood, social interaction, partner relationships, sexual dysfunction, and avoidance behaviors (Ayers, et al., 2006, Bailham \& Joseph, 2003, Nicholls \& Ayers, 2007). Avoidance behaviors that have been associated with childbirthrelated PTSD include avoidance of contact with the baby, avoidance of sexual intimacy, emotional numbing, avoidance of intrusive medical procedures, and fear of childbirth (Vythilingum, 2010).

The effects that have been studied will be considered in the literature review; however, it is important to note the absence of two key areas of research: (1) the relationship between PTSD and maternal self-efficacy, and (2) the relationship between PTSD and maternal appraisal of infant temperament. To date, no studies have examined the woman's perception of herself in the mothering role, or her perception of her infant. In one British study, it was reported that PTSD symptoms had a direct effect on the parent-baby bond; however, the investigators did not directly examine mothers' appraisal of infant temperament (Parfitt \& Ayers, 2009). It is also important to note that, in the comprehensive literature review on the subject of childbirth-related PTSD, less than $10 \%$ of the citations were comprised of U.S.-based research. This is important because the postpartum course, care, and intervention strategies differ greatly in the 
United States, when compared to practices in either Europe or Australia, where the majority of the studies were undertaken.

\section{Definition and History Self-Efficacy}

Self-efficacy is based on the work of Albert Bandura (1977) and social learning theory. Bandura (1995, p. 2) defined self-efficacy as "the belief in one's capabilities to organize and execute the courses of action required to manage prospective situations." Self-efficacy beliefs affect people's cognitions, motivations, affective processes, and ultimately their behavior (Bandura,1997).

In comparison to people with low levels of self-efficacy, people with high levels of self-efficacy are more likely to persevere in the face of difficulties, more likely to demonstrate intrinsic motivation when engaged and performing a task, and less likely to feel disappointed in the face of failure. They are less likely to feel stressed and more frequently perceive a vsituation as challenging as opposed to difficult. Moreover, setbacks and failure affect individuals with low levels of self-efficacy more strongly, even in the cases of mild failure.

Overall, in these circumstances individuals are slower to recover their sense of self-efficacy (Bandura, 1997). Bandura (1997) also suggested that self-efficacy should be regarded with respect to specific situations, and although he does note that selfefficacy in an area likely can transfer to related areas, he indicated that self-efficacy in unrelated areas develops rather independently.

\section{Parenting Self-Efficacy}

The concept of parenting self-efficacy was introduced by Teti and Gelfand (1991) in their study examining the idea that mothers' self-efficacy beliefs mediate the effects of 
variables such as depression, perception of infant temperament, and social-marital supports on parenting behavior. Parenting self-efficacy (PSE) is defined as "beliefs or judgments a parent holds of their capabilities to organize and execute a set of tasks related to parenting a child" (Salonen, et al., 2009, p. 2325). High parenting selfefficacy is important to the parents' sense of well-being and parenting satisfaction (Coleman \& Karraker, 1997, Drake et al., 2007), as well as predicting adequate parenting practices and behaviors (Jones \& Prinz, 2005). In one recent Canadian study, it was discovered that greater parenting self-efficacy at one month was predicted by having had a previous child/children and correlated with excellent partner relationship and maternal perception of infant contentment (Bryanton, et al., 2008). Parenting selfefficacy, specifically maternal self-efficacy, has also been shown to be affected by depression (Atkins, 2010), general self-efficacy and interpersonal relational functioning (Sevigny \& Loutzenhiser, 2010).

\section{Attachment and Infant Temperament}

The initial conceptualizations of temperament pre-date contemporary science, and can be traced back to the ancient world of Hippocrates. The ancient Greeks came up with two dimensions of temperament, leading to four "types," based on what kind of fluids (called humors) a person had in excess or in deficit. From that early introduction, the definition of temperament has continued to evolve throughout history. Many important theorists have contributed to our understanding of temperament including Carl Jung, a Swiss psychiatrist and early follower of Freud who took interest in discovering the depths of his own unconscious and those of his patients in a Zurich psychiatric hospital, and out of these experiences elaborated his psychology. While Jung paid 
homage to the ancient Greek concept of temperament, he differentiated his temperament theory as a psychological typology. Jungian psychological types served as a precursor to temperament as we now understand it. Jung postulated that each individual possesses the ability to exhibit temperament types which are opposites (e.g., introversion/extraversion); however, the individual possesses a propensity to exhibit one over the other (Jung, 1971/1921).

Another important name in the field of temperament study is William $\mathrm{H}$. Sheldon, an American psychologist, who introduced the idea that certain body types tended to be associated with particular personality traits. Sheldon's theory purported that there were three primary body types: ectomorph, mesomorph, and endomorph, and that each of the types had general temperament traits which accompanied it. The ectomorph (tall, thin, linear body type) was characterized by privacy, restraint and a heightened selfawareness; the mesomorph (hard, square, muscular body type) was said to be centered on assertiveness and a love of action; and the final type, the endomorph (soft, round, with body mass centered around abdominal area) Sheldon reported, was relaxed, comfortable, and fun-loving (Sheldon, 1940). German psychologist Hans Eysenck, a pioneer in the field of personality, introduced through factor analysis a system of categorizing temperament along two dimensions: introversion/extraversion and stability/neuroticism. Eysenck (1967) viewed temperament as being based primarily on physiology and genetics. He believed that some people have a more sensitive sympathetic nervous system than others and this explains the differences in temperament. Further developing the definition of temperament was Gordon Allport, an American psychologist whose work defined temperament through the lens of what he 
termed "personal dispositions." Allport (1961) further defined temperament as being an inherited biological basis and reported that infants interact and react to the environment and experiences in different ways, which are reflective of their temperament, or behavioral style (p.34). Infant temperament is thought to be determined through a complex interaction between biological factors and an ability of the infant to self-regulate emotions (Dave, et al., 2005). An infant's temperament can determine how s/he interacts with the environment, as well as later cognitive and social development (Tronick \& Field, 1986).

\section{Object relations theory}

The principles of attachment theory further support an understanding of infant temperament. A predecessor to attachment theory is the British school of thought known as object-relations theory, a psychodynamic theory asserting that psychological development proceeds in relation to significant figures in one's environment. The earliest object-relations theorists were Otto Rank and Sandor Ferenczi, who developed the theory in the 1920s, and then several decades later in the 1950s, the theory was further advanced by British psychologists Ronald Fairbairn, Donald Winnicott, and Melanie Klein (Holmes, 2001). Attachment theory has continued to further support the validity of the developmental progressions described in object relations theory.

\section{Konrad Lorenz}

Another precursor to the field of attachment theory was the work of Austrian zoologist and ornithologist Konrad Lorenz. Lorenz discovered the concept of imprinting, as he observed newly hatched ducklings and goslings, and their responses when subjected to an abnormal environment within the first critical hours after hatching. The 
young birds followed and appeared to become bonded to the first moving object they encountered. Lorenz was impressed by the fact that the animal does not instinctively recognize adult members of its species, but requires a special type of social learning to become bonded or attached to their own kind. Lorenz was instrumental in establishing an understanding that innate behaviors play a central role in the adaptations of organisms and the evolutionary process underlies the development of behavior (Hess, 1973).

\section{Attachment theory}

John Bowlby. John Bowlby, a British psychiatrist trained in Freudian psychoanalysis, is perhaps most notably associated with the concept of attachment. Bowlby created a theory explaining the interactions between human infants and their caregivers (Bowlby, 1973a). In Volume 2 of this work, Bowlby explained

A young child's experience of an encouraging, supportive, and cooperative mother, and a little later, father, gives him a sense of worth, a belief in the helpfulness of others, and a favorable model on which to build future relationships... by enabling him to explore his environment with confidence and to deal with it effectively, such experiences also promote his sense of competence. (p. 378)

Attachment has been defined as "phylogenetically programmed propensity of one person (usually a child) to bond to another who is viewed as stronger and wiser. Explicit in attachment theory is the notion that the attachment figure and the affectional bond cannot be replaced by another" (Carter, et al., 2005, p. 4). According to Bowlby (1982), human infants are born with a repertoire of proximity-seeking behaviors, which 
will insure that they are close by to those with whom they are attached. From evolutionary standpoint, this design is so that the infants are kept safe, secure, and well cared for.

Mary Ainsworth. Bowlby's work was operationalized by his followers, notably Mary Ainsworth. In her most famous work Patterns of Attachment: A Psychological Study of the Strange Situation, (Ainsworth, et al., 1978), she developed the Strange Situation test which categorized children's attachment style based on how they responded to separation and reunion with caretakers, as well as their reactions to strangers. Ainsworth (1970) identified three main attachment styles, secure, avoidant and resistant/ambivalent. She concluded that these attachment styles were the result of early interactions with the mother. In addition to attachment style, it has also been shown that cognitive and emotional aspects of women's subjective feelings are likely to underpin mother-infant attachments (Teti \& Galfand, 1997).

Biological basis for attachment. Also critical to the formation of attachment between infant and parent is some form of biological, as well as social, engagement. A combination of hormones and other relevant neurochemicals, namely endorphins, epinephrine and norepinephrine, and prolactin, work together during the labor, birth, and postpartum period that bring about a sense of calm and connection within the motherinfant pair (Moberg, 2003). Perhaps the best-known birth hormone is oxytocin, which is released during sexual activity, male and female orgasm, birth, and breastfeeding. Oxytocin engenders feelings of love and altruism; "Whatever the facet of love we consider, oxytocin is involved" (Odent, 2001, p.31). "Oxytocin is made in the hypothalamus, deep inside the mammalian brain, and stored in the posterior section of 
the pituitary, the master gland of the endocrine system, from where it is released in pulses" (Buckley, 2010, p.36). There is significant confusion and controversy regarding how oxytocin finds its way to the target tissues. It is manufactured in the supraoptic and paraventricular nuclei of the hypothalamus and stored in the terminal buttons on their axons (Herring bodies) in the posterior pituitary. It is released into common circulation from there. However, the blood-brain barrier prevents oxytocin from the circulation reentering the brain. The exact mechanisms are still unknown. In the minutes after birth, both mother and baby simultaneously release this hormone of "calm and connection" (Uvnas-Moberg, 2003). During that time, ongoing newborn oxytocin production is enhanced by skin-to-skin and eye-to-eye contact. Newborn levels subside during the first hour after birth, but are elevated above normal for at least four days (Leak et al., 1981). The hormones involved in the stress response can counter the effects of these calming hormones, making maternal-infant attachment a difficult task. They represent competing interests; while oxytocin attempts to lower activity in the amygdala, these "fight-or-flight" related hormones, epinephrine and norepinephrine, may be released at higher levels due to the mother's perception of fear, and cause a reduction in the release of oxytocin (Kirsch et al. 2005; Segal et al., 1998; Douglas et al., 2002).

Infant temperament. Infant temperament is thought to be determined through a complex interaction between the biological factors discussed above, and an ability of the infant to self-regulate emotions (Dave et al., 2005). Temperament is considered an innate tendency which influences how an individual behaves toward other persons and objects in his/her environment and how s/he is affected and shaped by his/her 
surroundings. An infant's temperament can determine how s/he interacts with the environment, as well as later cognitive and social development (Tronick \& Field, 1986).

Evaluation of infant temperament. The process of evaluating infant temperament carries a certain amount of subjectivity. While parent report instruments take advantage of the parent's extensive opportunities to observe the infant across a broad array of contexts, cautions regarding such instruments have been raised, with specific concerns regarding the potential error (Rothbart \& Bates, 1998). For example, error may occur due to the influence of social desirability, unfamiliarity with the behavior of other infants with whom the child is compared, and/or limited accuracy in the parent's perceptions involving the infant.

Factors affecting appraisal of infant temperament. There is research showing the detrimental effects of postpartum depression on maternal appraisal of infant temperament, as well as on maternal self-efficacy (Dieter et al., 2001; Milne et al., 2009). The reasons for this association are not completely clear, but it is believed to be related to the mother's view of self and world being negatively skewed, as well as impaired interactions between the depressed mother and child (Murray \& Cooper, 1997). While it would stand to reason that the same might be true for mothers who are affected by childbirth-related PTSD, there has been very little attention given to the course of this disorder and its effects on the mother-infant relationship, and more specifically on maternal appraisal of infant temperament.

Therefore, in the present study, I will examine the effects of childbirth-related PTSD on maternal self-efficacy and maternal appraisal of infant temperament. While substantial research exists in each of these individual areas, to date there have been no 
studies examining the effects that birth-related trauma may have on the mother-infant relationship or the woman's perception of herself as mother. Because trauma response has been shown in other instances to overgeneralize negative appraisals to seemingly non-related people and/or situations, it is hypothesized that this may be the case in mothers' appraisals of their infants' temperaments. While attachment theory research has waned over the past few decades, and the theory has been significantly modified as a result of empirical research, the concepts have become generally accepted (Rutter, 1995). Attachment theory has formed the basis of new therapies and informed existing ones, and its concepts have been used in the formulation of social and childcare policies to support the early attachment relationships of children. 


\section{CHAPTER 2: REVIEW OF LITERATURE}

\section{Prevalence and Predictors of Childbirth-Related PTSD}

Childbirth-related PTSD is a relatively new area of research interest, with the vast majority of studies having taken place from 1997- to the present. Studies from various disciplines and cross-culturally suggest that the prevalence rate of PTSD following childbirth falls in the range of $3-9 \%$, with up to another $20-40 \%$ of women being partially symptomatic for the disorder (Ayers, 2004; Ayers et al., 2008; \& Olde et al., 2006). Alcorn, et al. (2010) examined the course of 933 Australian women during pregnancy, at 4-6 weeks, 12 weeks, and 24 weeks postpartum. The researchers found that, when controlling for PTSD and partial PTSD due to previous traumatic events as well as clinically significant anxiety and depression during pregnancy, PTSD rates were $1.2 \%$ at 4- 6 weeks, $3.1 \%$ at 12 weeks and $3.9 \%$ at 24 weeks postpartum. This is among the first of several studies examining the occurrence of full criteria PTSD resulting from childbirth, after controlling for pre-existing PTSD and partial PTSD and clinically significant depression and anxiety in pregnancy. Although the study was able to contribute relevant clinical research to the field, it also has some limitations. The variables of PTSD and partial PTSD due to previous traumatic events were not well defined or operationalized, but were instead defined through a non-standardized selfreport measure completed by participants. Also, this study, like most of the studies in the field of childbirth-related trauma, were carried out using non-U.S. samples, (in this case Australia), where labor and birth practices are vastly different than in the U.S., which presents a challenge when attempting to generalize results to a North American population. Some examples of these differences in practice include: utilization of 
midwives as primary care providers, with obstetricians being involved only in high risk or otherwise specialized cases; differences in frequency and method of operative delivery; difference in frequency of out-of-hospital birth; differences in screening for postpartum mental illnesses; and quality of postpartum social support as a cultural norm.

Soderquist et al. (2006) examined the longitudinal course of childbirth-related trauma. Posttraumatic stress was assessed in early and late pregnancy, and 1, 4, 7, and 11 months postpartum by means of questionnaires among 1,224 women. Thirtyseven women (3\%) met criteria for posttraumatic stress disorder at least once within 111 months postpartum. The study found that, as measured in early pregnancy, previous counseling related to pregnancy/childbirth was associated with an increased risk of having posttraumatic stress within the postpartum period, as were: having depression in early pregnancy, 'pre'-traumatic stress, and severe fear of childbirth in late pregnancy. Also, women with posttraumatic stress within 11 months postpartum showed less social support averaged over the postpartum period than women without posttraumatic stress. This study served as an important addition to the body of knowledge on the topic of childbirth-related trauma because of its longitudinal nature. Variables were examined at different points during pregnancy, in addition to several times during the postpartum period. Notably though, the study was carried out in Sweden, with a completely Swedish sample, whose birth practices and experiences are different from North American women. One statistic regarding birth differences is that in Sweden, $98 \%$ of births are attended by midwives, in comparison to $8 \%$ of births in the United States (Kaiser, 2011, para. 7). Another shortcoming of the study was lack of a 
clearly-defined measure of perceived social support, and how that was operationalized by the researchers.

One recent study which utilized a North American sample (Beck et al., 2011) conducted a survey of 1,373 women and reported that $9 \%$ of the sample met full diagnostic criteria for PTSD, while another $18 \%$ of women scored above the cutoff score, indicating that they were experiencing elevated levels of posttraumatic stress symptoms. The variables which were significantly related to elevated posttraumatic stress symptoms/levels included: low partner support, elevated postpartum depressive symptoms, more physical problems since birth, and less health-promoting behaviors. Additionally, eight variables significantly differentiated women who had elevated posttraumatic stress symptom levels from those who did not: no private health insurance, unplanned pregnancy, pressure to have an induction and epidural analgesia, planned cesarean birth, not breastfeeding as long as wanted, not exclusively breastfeeding at one month, and consulting with a clinician about mental well-being after the birth. This study is clearly more applicable, in that it utilized a North American sample of women; however, the survey was designed as a forum for women to discuss their birth experiences, aspects of their experiences therein, and "have a voice," potentially increasing the likelihood that women who had particularly extreme experiences, either negative or positive, may be overrepresented in this study.

\section{Effects of birth-related PTSD}

Throughout the relatively short history of studying PTSD as it relates to traumatic birth, a number of effects have been shown to be associated with the disorder. In a qualitative study utilizing a semi-structured interview, Ayers et al. (2006) reported that 
"childbirth-related PTSD was found to have wide-ranging effects on women and their relationships. Women reported changes in physical well-being, mood, behavior, social interaction, and fear of childbirth" (p.392). They also reported negative effects on their relationship with their partner, including sexual dysfunction, disagreements, and blame for events of birth. Nearly all women in the study reported initial feelings of rejection towards the baby, although this changed some over time. This same study concluded that the women seemed to have either avoidant or ambivalent attachment with their infants. While the results of this qualitative study are meaningful, the findings need to be placed in the context of the effects of normal birth on women, examining how likely it is that giving birth and coping with a new baby would put strain on partner relationships, women's views of themselves as competent parents, as well as effects on the motherbaby relationship.

In another European study, Ayers et al. (2007) found that postnatal psychopathology, specifically PTSD, was associated with interference with mother-baby bonding and resulted in the mothers evaluating their infants more negatively. However, the measures used to observe the mother-baby bond was adapted from an observational measure and had not been tested against other measures, resulting in a lack of concurrent validity. In addition to problems with the measure, this study was also limited by a low response rate; the sample could have provided results that are not generalizable. Finally, the parent-baby bond is a related, yet distinct, construct from that of infant temperament which is what I intend to measure in the present study. 


\section{Relationship between PTSD and Self-Efficacy}

According to Social Learning Theory, self-efficacy beliefs represent a cluster of cognitions, crucial for mental health and posttraumatic adaptation (Benight \& Bandura, 2004). Self-efficacy cognitions are affected by the individual's experiences, but in turn they determine well-being and the perceived ability to master challenging demands by means of adaptive actions is therefore reflected. Self-efficacy may be seen as a proximal determinant of health-related outcomes of a traumatic event (Benight \& Bandura, 2004).

While the field of childbirth-related PTSD among mothers is relatively new, PTSD as a mental health diagnosis has been around for nearly 30 years, so much of what is known about its effects can be examined and applied to the disorder as it relates to birth. And while the specific relationship between parental self-efficacy and posttraumatic stress reactions has not been examined previously, similar constructs have shown to be correlated in the literature. One such investigation found a significant correlation between the influence of self-regulation processes and self-esteem on the posttraumatic adaptation process (Foa et al., 1994). In another example, Regehr et al. (2000) found that patients showing marked symptoms of posttraumatic stress following accidental injury (the "highly symptomatic group") also had a low "sense of coherence." Flatten et al. (2008) observed that in patients being treated for severe burns on an inpatient burn unit, the development of PTSD was inversely related to decreased selfefficacy. Heinrichs et al. (2005) studied a sample of firefighters, and found that a low level of self-efficacy and a high level of hostility accounted for $42 \%$ of the variance in posttraumatic stress symptoms after a work period of two years. Further, Frommberger 
et al. (1999) demonstrated that the Sense of Coherence Self-Rating Scale correlated negatively with the development of posttraumatic psychopathology and psychological disorders.

While childbirth-related PTSD shares many traits in common with PTSD resultant from various other traumas, it also is unique in that avoidance of trauma-associated cues may not be possible, as the infant may serve as a reminder of the trauma. Consequently, women may report feeling guilty for associating the infant with the traumatic event (Alder et al., 2006).

\section{Other Disorders and Effects on Self-Efficacy and Mother-Infant Relationship}

To date, research examining the adverse effects of maternal psychopathology on the characteristics of the early mother-infant relationship has focused mainly on postnatal depression (Davies et al., 2008). Regarding the mother-infant dyad, Bailham and Joseph (2003) observed that women who develop PTSD symptoms following childbirth may experience co-morbid problems in terms of their perception of the quality of their relationship with their infants. In determining the quality of the early dyadic relationship, Teti and Galfand (1997) emphasized the role of maternal cognitions and maternal appraisal of their infants.

In the parenting context, self-efficacy has been defined as "parents' self-referent estimations of competence in the parental role" (Coleman \& Karraker, 2003, p.128). Parenting self-efficacy beliefs can be domain-specific or domain-general. Domainspecific self-efficacy beliefs focus on the extent to which a parent feels competent in the role in specific domains, whereas domain-general self-efficacy beliefs refer to the parent's overall self-perceived competence in the parenting role (Dumka et al., 1996). 
For the purpose of the present study, I reviewed the literature pertaining to domaingeneral parenting self-efficacy. Research has suggested that persons who are high in self-efficacy are more persistent when facing difficulties or challenges (Coleman \& Karraker, 1997; Teti \& Gelfand 1991), more positive, and are more likely to initiate productive courses of action and adaptive coping (Coleman \& Karraker, 1997). In contrast, persons who believe they cannot produce the desired results by their actions or believe they are unable to complete the actions necessary to achieve the desired outcome have little incentive to persevere when faced with obstacles (Bandura et al., 1999). Thus, self-efficacy determines whether necessary coping behaviors will be initiated and how long they will be maintained (Zeiss et al., 1999). Regarding the transition to parenthood, mothers who feel they lack the ability to quiet a crying baby, for example, are less likely to make legitimate attempts to placate the child and are more likely to give up quickly if the child does not soothe immediately. Consequently, when perceived failure ensues, low self-efficacy beliefs are confirmed, resulting in negative affect and depression (Coleman \& Karraker, 1997).

"Self-efficacy also is a crucial determinant of emotional reactions to situations, as high and low self-efficacy are associated with positive and negative affect, respectively" (Zeiss et al., 1999, p. 228). Numerous studies have demonstrated a relationship between higher maternal self-efficacy and lower levels of postpartum depression (Coleman \& Karraker, 1997; Donovan et al., 1990; Jackson, 2000; \& Teti \& Gelfand, 1991). The findings from these studies have supported the role of self-efficacy in personal agency in new mothers. When faced with stressful situations, mothers low in self-efficacy give up more readily and assign internal reasons for failure, resulting in 
negative affect (Jackson, 2000). In contrast, mothers high in self-efficacy are more confident, make internal assignments of success, and therefore experience less negative affect (Bandura, 1982). Given this, it is likely that mothers who have experienced childbirth-related PTSD will be shown to have a lower sense of selfefficacy, as in the case with postpartum depression. It is hypothesized that mothers who score higher on a measure of childbirth-related trauma will have lower scores on a measurement of maternal self-efficacy.

Factors Related to Mothers' Appraisal of Infant Temperament

"Parents' perceptions of their child are of great importance, regardless of whether, objectively evaluated, they are correct or not" (Mantymaa et al., 2006, p. 382). This is the case because, as researchers point out, "parents act in a way that elicits from their infants behavior that meets their expectations" (Mebert, 1991, p. 357). Mantymaa et al. (2006) found that when infants categorized as difficult were observed, mothers' intrusiveness and infants' poor interactive behavior in early mother-infant interaction, as well as parental distress significantly increased the infants' risk of being perceived as difficult. However, the study did not specifically examine mothers who were experiencing childbirth-related PTSD. Because of the high level of parental distress in the disorder, though, it is likely that mothers who experience childbirthrelated PTSD will rate their infants' temperament more negatively.

\section{Summary and Statement of the Problem}

In summary, findings from the relevant literature suggest a relationship between PTSD and subsequent negative appraisal of one's abilities, as well as a negative perception of and interaction with circumstances associated with the PTSD event. While 
there is research correlating the presence of other mental health disorders to parental self-efficacy and appraisal of infant temperament, to date there are no studies that have examined whether this is the case in childbirth-related PTSD. In this study I aim to investigate the prevalence of childbirth-related trauma and to examine whether the presence of trauma has an impact on mothers' perceived parental self-efficacy and appraisal of their infants' temperaments. The importance of the study is two-fold, in that it adds to the current body of research regarding childbirth-related PTSD and fills in a gap currently in the field, and it can also provide useful clinical data for treatment and management of postpartum PTSD. It may serve as an impetus to treat childbirthrelated trauma in order to promote normal mother-infant attachment, as well as to provide validation for parenting skills training which will increase self-efficacy.

\section{Research Hypotheses}

Hypothesis 1: It is expected that an inverse relationship will be found between the predictor variable, a participant's score on a measure of childbirth-related trauma (TESB) and the criterion, her score on the Parenting Sense of Competency Scale (PSOC), a measure of parenting self-efficacy. An individual's score on the TES-B will serve as a significant predictor of her score on the PSOC. Individuals with higher scores on the trauma measure will exhibit significantly lower parental self-efficacy scores than those with lower scores on the TES-B.

Hypothesis 2: It is expected that an inverse relationship will be found between the predictor variable, a participant's score on a measure of childbirth-related trauma (TESB) and the criterion, her score on the Infant Behavior Questionnaire-Revised (IBQ-R), a measure of infant temperament appraisal. An individual's score on the TES-B will serve 
as a significant predictor of her score on the IBQ-R. Individuals with higher scores on the trauma measure will get lower scores on the IBQ-R, which represents a more negative perception of the infant's temperament. 


\section{CHAPTER 3: METHOD}

\section{Participants}

Participants in the current study were recruited using social media, including online listservs and websites for new mothers. To recruit participants online, an email was sent by the investigator to online listserv groups including: the Midwives Alliance of North America, International Cesarean Awareness Network, posttraumatic stress online group, and a social networking website. All potential participants were provided with a description of the study, documentation of Institutional Review Board (IRB) approval (Appendix G), a list of resources for postpartum support, and a link to the online survey.

Participants were required to have met the following criteria: have given birth to a live (singleton) infant 3 to 12 months prior to taking the survey; be over 18 years of age; have access to an online source to complete the surveys; and be fluent in written English. These criteria were included in the survey, and surveys completed by persons who did not meet these criteria were not considered in the data analysis.

Sample origin. "In planning a study...you must estimate what constitutes a reasonable minimum effect that you wish to detect, a minimum power to detect that effect, and the sample size that will achieve that desired level of power" (Statsoft, 2011, para. 6). An effect size is a measure that describes the magnitude of the difference between two groups. According to Cohen (1992), effect sizes are categorized into small $\left(f^{2}=.02\right)$, medium $\left(f^{2}=.15\right)$, and large $\left(f^{2}=.35\right)$, where $f^{2}$ is calculated using $R^{2}$ values derived either from an ANOVA or Multiple Linear Regression. Typically, investigators accept a beta error rate of $20 \%$, which corresponds with a study power of $80 \%$ (Lochner, et al., 2001; Streidel, 1990). The sample size for the current study was 
calculated using $\mathrm{G}^{*}$ Power 3 , with alpha level $=.05$ and power $=.80$, entering 11 predictor variables (the TES-B score, the three continuous variables on the demographics page, plus seven categorical variables that were dummy coded for the proposed analysis). Because effect size can only be calculated after data has been collected from program participants, an estimate used for the power analysis was $f^{2}=$ .15 , indicating a medium effect size, which yielded a sample size of $n=153$. This selection of medium effect size was based on the need for balance between the size of the effect that we can detect, and the resources available for the study.

"It is usually possible to perform a power analysis based entirely on a logical assessment of what constitutes a clinically (or theoretically) important effect. The effect size should represent the smallest effect that would be of clinical or substantive significance." (Biostat, 2012, para.7).

Prior research in the field (Ayers et al., 2007; Beck et al., 2011; Soet et al., 2003) was also considered when deciding that a medium effect size is appropriate for the current study.

\section{Design}

A prospective, exploratory research design was used in the present study. The study was outlined in the cover letter (Appendix E) and participation was voluntary. The online documents included the explanatory cover letter, a copy of IRB approval, and each of the four surveys, along with a resource guide at the end of the packet.

Validity. Potential threats to validity exist within the study design, including the possibility of an overrepresentation of certain groups of women, namely those who utilize midwifery services, those with internet access who may be seeking resources 
and support for trauma, and those from certain geographical areas. This is due to the recruitment sources utilized. While an oversampling of women with PTSD may present a potential threat to validity, it is unlikely that this would be the case, but instead it may work as an advantage in assuring that there will be adequate numbers of women with trauma symptoms for data analysis. Regarding the oversampling of the other groups, efforts were made to minimize these threats by including women whose care provider is an obstetrician working in a more densely populated location. If the sample were to be unacceptably skewed due to these limitations, then there would have been a decrease in the generalizability of the study results to a broader population. All participants remained anonymous, and the confidentiality of the data was maintained by password protection, stored on USB and/or personal hard drives. The secure data was utilized only for the present study and accessed by only the principal investigator and coprincipal investigator or authorized personnel. The data will be kept securely for a period of time, adhering to university guidelines, and destroyed accordingly.

Another potential threat to validity in the present study is omitted variable bias, meaning that there could be a variable that was not included in the study which could have changed the outcome of the results. I attempted to control for this by including as many variables as were thought to be potentially relating to the outcome. Errors-invariables bias could also have posed a threat to the validity of the study if the demographic questionnaire was not specific enough or detailed enough to garner important data about each variable. For example, rather than the choices for the mode of infant feeding question being categorized as breast, bottle, combination, it may have needed to have been broken down more specifically, asking about the participant's 
qualitative experience with infant feeding (eg. "Did you have difficulty with your preferred method of infant feeding?"). While this threat was not completely eliminated, the researcher made attempts to include enough specificity in response choices to minimize the threat, while at the same time making the questions general enough to not become confusing to participants. Finally, the present study could have simultaneous causality bias where, rather than the IV being predictive of the DVs, the possibility exists that lower levels of self-efficacy could have caused a greater likelihood that the participant would experience a traumatic birth in the first place. The current research is built upon the foundation of previous studies in the field, which led to the development of the predictors and criterion variables used in this study, and while correlation does not imply causation, it was hypothesized that the participant's trauma score would be predictive of both her self-efficacy score and her appraisal of infant temperament score.

\section{Measures - Predictors}

Demographic and obstetric information. An informational questionnaire of demographic and obstetric information was used to collect data about age of mother, age of infant, mother's highest education level, ethnic group, marital status, parity, mode of delivery, mode of infant feeding, and place of birth (See Appendix A). Selection of these variables was based on previous studies which have suggested their association with childbirth-related trauma (Ayers et al., 2005; Bailham \& Joseph, 2003; Creedy et al., 2000) Descriptive statistics were reported for each of these nine variables in addition to their inclusion in the regression equations used for the data analysis.

Traumatic Event Scale-Version B (TES-B). Women's experience of trauma was assessed using the Traumatic Event Scale-B (TES-B) developed by Wijma et al. 
(1997) for use specifically in researching posttraumatic stress disorder resulting from childbirth (See Appendix B). The scale is based on the DSM-IV-TR criteria for PTSD diagnosis and encompasses all symptoms and criteria. The first section of the TES-B, based upon DSM-IV-TR Criterion A (traumatic experience), includes four statements, asking subjects to respond according to how they felt during delivery: (1) "the childbirth was a trying experience"; (2) "the childbirth was a threat to my physical integrity"; (3) "during the childbirth I was afraid that I and/or my baby was going to die or be seriously harmed"; (4) "during the childbirth I felt anxious/helpless/horrified". These items are rated on a 4-point Likert-type scale ranging from 1, not at all, to 4, very much. For an experience to be classified as traumatic, a woman has to indicate that both aspects of the DSM-IV event criteria are met (threat and emotional response). If the participant responds positively (much or very much) to questions 1 (a trying experience) or 3 (threat to physical integrity of self or baby), the threat criterion is met; if she responds positively to questions 2 (feeling physically offended or violated) or 4 (experienced anguish, helplessness, horror), the emotional response criterion is met. The TES-B then goes through Criteria B-D of the DSM-IV diagnostic requirements. This part consists of 17 items that measure intrusion, avoidance, and arousal symptoms. Most items (10 of 17) are specific to the birth experience, with the remaining seven items being more general. The items all utilize a 4-point scale ranging from 1, not at all, to 4 , often. The scores were added and then divided by the total number of items to determine the woman's score, which will range from 1 to 4 , with lower scores representing lower trauma experience. If a participant failed to answer three or fewer items, the score was divided by the number of questions that were answered and the 
test protocol was included in data analysis. If a participant failed to answer four or more items, the test protocol was not included for data analysis.

As an estimate of the internal consistency of the TES-B, Cronbach's alpha was calculated at 0.87 (Stamrood et al., 2010). This is similar to measured internal consistency (0.84) reported by the test authors (Wijma et al., 1997). With regard to validity, when the dimensional structure of the 17 symptom-items of the TES-B was evaluated by means of Principal Components Analysis (PCA), loadings on all items was sufficient, range $.41-.70$. (Stamrood et al., 2010). PCA is a way of identifying patterns in data, and expressing the data in such a way as to highlight their similarities and differences. The purpose of PCA is to reduce the complexity of the data into the principal components. PCA divides all the variance contained in the correlation matrix, extracting however many components are required to do so, with the aim being to explain the percentage of variability with the least number of components. The PCA on this particular measure (TES-B) indicates that the instrument is sufficient to identify DSM-IV-TR based PTSD symptoms using 17 items.

\section{Measures--Criterion}

Parenting Sense of Competence Scale (PSOC). The Parenting Sense of Competence Scale, PSOC (Johnston \& Mash, 1989), is an instrument for measuring parental self-efficacy (See Appendix C). It is a 17-item scale designed to assess domain-general satisfaction and self-efficacy in the parenting role. There is a version of the scale for mothers and a version of the scale for fathers, and PSOC items are appropriately phrased for the parent completing the questionnaire (e.g. "My mother was better prepared to be a good mother than I am"). Parents indicate their level of 
agreement with each item on a 6-point Likert-type scale, ranging from 1, strongly agree, to 6 , strongly disagree. While the 17 items present as one scale to the participant, inherent to the instrument are two distinct scales: Satisfaction Scale and Efficacy Scale. An example of an item on the Efficacy subscale is "Considering how long l've been a mother, I feel thoroughly familiar with this role." The scores for each item were added together and divided by the total number of items, for a possible score range from 1 to 6 on the Efficacy subscale, with lower scores representing lower parenting self-efficacy. If a participant failed to answer three or fewer items, the score was divided by the number of questions that were answered and the test protocol was included in data analysis. If a participant failed to answer four or more items, the test protocol was not included for data analysis.

Acceptable levels of internal consistency, ranging from Cronbach's $\alpha=0.75-0.88$, have been reported for the PSOC in a number of studies (Johnston \& Mash, 1989; Lovejoy et al., 1997; and Ohan et al., 2000). In examining the validity of the PSOC, Ohan et al. (2000) looked at relationships with aspects of family life, and it was found that internalizing and externalizing child behavior problems was negatively related to parents' reports of their liking of the parenting role (Satisfaction) but not in their perceived competence in the parenting role (Efficacy). This was done by calculating partial correlations between Efficacy and Satisfaction PSOC scores and other measures of family functioning, controlling for the shared variance between the two scales. To date, the validity has not been examined in a sample of parents with infants, the population from which the sample was derived for this study. In the present study, only the Efficacy Scale was used $(\alpha=.76)$. The numerical representations derived from 
the Likert items were added together and divided by the total number of responses to derive a mean score for each participant on the PSOC.

Infant Behavior Questionnaire-Revised (IBQ-R) Very Short Form. The Infant Behavior Questionnaire-Revised, IBQ-R (Rothbart, 1981) is a widely used parent measure of infant temperament (See Appendix D). The Very Short Form was derived from the original IBQ-R and contains thirty-seven items concerning infant temperament, which are rated on a 7-point Likert-type scale from 1, never to 7, always. The items are divided and scored on three scales. Surgency reflects high levels of activity, positive emotion, and engagement with the environment. Negative Affect is the second scale. An example of an item on the Negative Affect Scale would be: "When tired, how often does your baby show distress?" The mothers are asked about the relative frequency of occurrence of specified infant reactions in specific situations during the previous 1 to 2 weeks. Items on the Negative Affect scale are negatively loaded, whereas scores on the other two scales are positively loaded, so the Negative Affect scale items will be "reverse coded" to be consistent with the other two scales. Effortful Control comprises the ability to sustain focus on a task, to shift attention from one task to another, to initiate action, and to inhibit action. The items were totaled for all three scales to come up with an overall temperament score, with higher scores indicating more positive temperament. Several studies have provided evidence of good internal consistency, with Cronbach's a ranging from 0.71-0.83 (Bridges, et al., 1993; Reznick, et al.,1989). Gartstein, Putnam, Becken-Jones and Rothbart (2002) reported intercorrelations between the IBQ-R scales, which provides support for reliability and mono-method discriminant validity for the IBQ-R. Correlations between the IBQ-R scales, and 
conceptually/theoretically similar indicators were generally significant, supporting convergent validity for the instrument. Similar to the scoring on the PSOC as described previously, numerical representations for the Likert items were used, the scores for each question were added together and divided by the total number of completed questions, to come up with a mean score for each participant, ranging from 1 to 7 , with higher scores indicating more positive infant temperament. As instructed in the scoring guide for this instrument, questions which are answered 'N/A' were not be included for data analysis purposes.

\section{Procedures}

Approval to conduct the study was obtained from West Virginia University Institutional Review Board (IRB). The recruitment letter and URL of the survey (See Appendix E) was posted on relevant websites and listservs www.ican-online.org, www.mawv.org, http://health.groups.yahoo.com/group/ptsdafterchildbirth/, Facebook groups for: Community School of Midwifery, Sacred Mountain Midwifery School, and Midwives Alliance of North America, advertising to women who have had a baby within the past 3 to 12 months, who are interested in participating in a survey. Upon logging in to Qualtrics, participants were able to view an informational page, detailing the aim of the study, as well as an estimation of time needed to complete the survey. The cover page also explained anonymity and confidentiality, and assigned each participant an identification number (Appendix F). Participants were informed that they may discontinue the survey, withdrawing from the study, at any time. Participants were then asked to indicate their willingness to participate before completing the questionnaires. Once the participant had read the informational page, if she checked "I wish to 
participate in this study," she was then taken to the second page, which was the demographics data form. Once the participant finished the demographics page and all three survey instruments, she arrived at a page listing websites and resources for birth trauma and PTSD. Once the data was obtained from the targeted number of participants, SPSS was used to enter and analyze the data. This study presented minimal risk for harm to the participants. The magnitude of harm or discomfort presented to participants would hardly be more than is experienced in daily life. Participants were informed that the survey is completely voluntary and that they were free to discontinue the survey at any time. One potential risk is that the survey could serve as a reminder or trigger of a participant's experience of trauma; there was a list of trauma treatment resources was attached to the end of the survey (See Appendix G).

Data Analysis. "Multiple linear regression is a statistical technique that allows us to predict someone's score on one variable on the basis of their scores on several other variables" (Brace et al., 2012, p. 206). Such is the case in this study where the demographic variables plus the participant's TES-B score will be used to predict the scores on the PSOC, and separately on the IBQ-R. A backward stepwise method was employed in the analysis of data. Stepwise methods are useful for exploratory model building, where there has not yet been a body of sound theoretical literature available upon which to base the model (Wright, 1997, p. 181), which is consistent with the present study. Because there was a relatively modest-sized set of potential variables from which to eliminate a few, backward stepwise method was chosen over forward stepwise method. 
The first step of the data analysis phase was scoring each of the instruments for each participant. Of the demographic variables, five were coded as dummy variables for the sake of the analysis: Partner Status (single, partnered); Race (white nonHispanic, Hispanic, African American, Asian, Hawaiian/Pacific Islander, Other); Education (some college, college degree, graduate degree); Place of Birth (home, hospital, birthing center, other); Mode of Delivery (vaginal, planned Cesarean section, unplanned Cesarean section, Vaginal birth after Cesarean [VBAC]); and Mode of Infant Feeding (breast, bottle). For each of these categorical variables, I counted the number of groups to recode and subtracted $1(k-1)$, then created that number of new variables, the dummy variables. The remaining demographic variables were entered as continuous variables (Gestational Age at Time of Delivery, Age, and Prior Number of Births).

The other predictor variable that was used in this analysis was the participant's score on the TES-B. In scoring the TES-B, each item's score was added and then divided by the total number of items, yielding a total score between 1 and 4 , with higher scores indicating higher incidence of trauma, as discussed above.

The criterion variable in the first analysis was the participant's score on the Efficacy subscale of the PSOC. The PSOC consists of two subscales: Satisfaction and Efficacy. For the present study, only the Efficacy subscale was used in the data analysis, since the items on this scale were "empirically selected to reflect the degree of perceived skill, familiarity and ease in the parenting role" (Johnston \& Mash, 1989), which is what the present study was attempting to measure. The mean score was calculated for each participant and entered into SPSS as a criterion variable, with higher 
scores indicating higher parenting self-efficacy, as discussed above. Likewise, the IBQ$\mathrm{R}$ mean scores were calculated for each participant and entered as a criterion variable for a separate analysis, with higher scores on the IBQ-R indicating more positive infant temperament appraisal. Once descriptive statistics were calculated for demographic, obstetric, and event characteristics variables, these variables along with the participant's TES-B score were entered in a backward deletion stepwise regression analysis as predictor variables and regressed onto the participant's PSOC score. In this type of analysis, the SPSS program begins by placing all predictors in the model and then evaluates the contribution of each one to the model. This is done by examining the predetermined partial F-test significance value for each predictor in the model. If the partial $F$-value falls below this predetermined criterion it is removed from the equation. If it exceeds the criterion it is retained in the next iteration. This process repeats until no variable meeting the " $F$ to remove" and " $F$ to retain" remains to be tested. In this study I am using "greater than or equal to 5\%" explained variance to enter and "less than or equal to" $10 \%$ to remove. The entire backward stepwise deletion procedure will be repeated in a separate analysis, using the participant's IBQ-R score as the criterion variable The regression equation for each of the two statistical analysis procedures will take the general form $Y=\alpha+\beta_{1} x_{1}+\beta_{2} x_{2}+\ldots+\beta_{k} x_{k}$, where $\alpha$ is the constant, $B_{1}$ is the slope for $x_{1}, B_{2}$ is the slope for $B_{2}$ and so on. In each of the two equations, $x_{1}$ is "score on TES-B", $x_{2}$ is "participant age," $x_{3}$ is "highest educational level completed," $x_{4}$ is "number of prior births," $x_{5}$ is "gestational age at time of delivery" and likewise for each specific number of dichotomous variables of the dummy coded categorical variables. In the first analysis $Y$ represents the participants' score on the Efficacy scale 
of the PSOC, whereas in the second analysis $Y$ represents the participant's score on IBQ-R.

Certain assumptions of multiple linear regression must be met by the data, including: linearity, independence of the errors (no serial correlation), homoscedasticity, and normality. If the residuals are not normally distributed, this can distort relationships and significance tests. The residuals in the present study were examined for normality in several ways: visual inspection of the data, SPSS estimates of skewness and kurtosis, as well as performing a Kolmogorov-Smirnov test through SPSS, which provided inferential statistics of normality.

Cook's distance and Mahalanobis are approaches often used to detect outliers, and were utilized in the current study. Cook's distance is a commonly used estimate of the influence of a data point when performing least squares regression analysis. It measures the effect of deleting a given observation. The Mahalanobis distance accounts for the variance of each variable and the covariance between variables. Geometrically, it does this by transforming the data into standardized uncorrelated data and computing the ordinary Euclidean distance for the transformed data. Outliers in the data set were inspected and if the individual cases appeared to be exerting undue influence on the results, the data was then re-analyzed without the most severe outliers and compared with the entire data set to determine the degree of influence being exerted.

Multiple linear regression accurately estimates the relationship between the criterion and predictor variables if the relationship is linear in nature. If the relationship is non-linear, the results of the regression analysis may underestimate the relationship. 
Pedhazur (1997) suggests an examination of the standardized residual plots in order to test the linearity of the data, which will be performed using the SPSS software, along with the consideration of previous research to inform current analyses. The DurbinWatson statistic was used to establish whether the residuals are uncorrelated and the assumption of independence is upheld. The Durbin-Watson statistic is always between 0 and 4. A value of 2 means that there is no autocorrelation in the sample. Values approaching 0 indicate positive autocorrelation and values toward 4 indicate negative autocorrelation.

Homoscedasticity means that the variance of errors is the same across all levels of the independent variable. According to Tabachnick and Fidell (2013), when heteroscedasticity is marked it can lead to serious distortion of findings. Heteroscedasticity can also be a byproduct of a significant violation of the linearity and/or independence assumptions, in which case it may also be fixed as a byproduct of fixing those problems.

Multicollinearity is the undesirable situation where the correlations among independent variables are strong. In the present study, the VIF (Variance Inflation Factor) was tested using SPSS. VIF measures how much the variance of the estimated coefficients are increased over the case of no correlations among the $x$ variables. If there are two or more variables that have a VIF equal to or greater than 5 , one of these variables is to be removed from the regression model.

Following these analyses, the results were tabulated and reported. Beta coefficients for the independent variables and their standard errors were evaluated and reported using standard $t$-test procedures at $p \leq .05$, along with $R^{2}$, and goodness-of-fit 
statistics. The variables that were not significant predictors were reported, as well as those predictors that were significant, if any. Results are discussed in detail, along with limitations of the present study and possible directions for future research. 


\section{CHAPTER 4: RESULTS}

The aim of this study was to examine birth trauma, maternal self-efficacy, and appraisal of infant temperament. In the first analysis I examined whether a mother's assessment of her level of birth trauma, along with several demographic variables, could successfully predict her level of maternal self-efficacy. In a second analysis I examined whether a mother's level of birth trauma, along with demographic variables, could predict her appraisal of infant temperament.

\section{Sample Characteristics}

Participants completed a series of online surveys using Qualtrics. Inclusion criteria, which were given in the introductory statement, stated that the participant must 18 years of age or older, be proficient in English and must be the mother of a live singleton infant, aged 3-12 months. Two hundred twenty surveys were submitted. Incomplete surveys were removed leaving a total sample size of 168 , for a completion rate of 76 percent. A demographic questionnaire (See Appendix A) was completed which included age (Range $=20$ to $44, M=30.73, S D=4.758)$, number of prior births (Range $=0$ to $7, M=0.95, S D=1.247)$, gestational age at time of delivery (Range $=32$ to 44 weeks, $M=39.61, S D=1.970)$, race $(94 \%$ Caucasian, $1.2 \%$ African American, 1.2\% Asian, 1.2\% Hispanic, 0.6\% Pacific Islander, 1.8\% other), partner status (97.6\% partnered, $2.4 \%$ single), highest level of education ( $0.6 \%$ less than high school, $4.8 \%$ high school diploma or GED, $17.3 \%$ some college, $9.5 \%$ associate's degree, $38.1 \%$ bachelor's degree, $23.2 \%$ master's degree, $6.5 \%$ doctorate degree or higher), primary mode of infant feeding ( $82.7 \%$ breastfeeding, $6 \%$ bottle feeding, $11.3 \%$ combination), place of birth (66.7\% hospital, $29.8 \%$ home, $3.0 \%$ birthing center, $0.6 \%$ other), mode of 
delivery (3.6\% planned Cesarean section, 23.8\% unplanned Cesarean section, $64.3 \%$ vaginal birth, 8.3\% VBAC (vaginal birth after Cesarean)). Summary in Table 1 and 2.

Table 1

Demographics of Participants - Categorical Variables ( $n=168)$

\begin{tabular}{|c|c|c|c|}
\hline Characteristic & & Frequency & Percent \\
\hline \multicolumn{4}{|l|}{ Place of birth } \\
\hline & Hospital & 112 & 66.7 \\
\hline & Home & 50 & 29.8 \\
\hline & Birthing center & 5 & 3.0 \\
\hline & Other & 1 & .6 \\
\hline \multicolumn{4}{|c|}{ Mode of delivery } \\
\hline & Planned Cesarean & 6 & 3.6 \\
\hline & Unplanned Cesarean & 40 & 23.8 \\
\hline & Vaginal Birth & 108 & 64.3 \\
\hline & VBAC & 14 & 8.3 \\
\hline \multicolumn{4}{|l|}{ Race } \\
\hline & Caucasian & 158 & 94.0 \\
\hline & African American & 2 & 1.2 \\
\hline & Asian & 2 & 1.2 \\
\hline & Hispanic & 2 & 1.2 \\
\hline & Pacific Islander & 1 & 6 \\
\hline & Other & 3 & 1.8 \\
\hline \multicolumn{4}{|l|}{ Partner Status } \\
\hline & Single & 4 & 2.4 \\
\hline & Partnered & 164 & 97.6 \\
\hline \multicolumn{4}{|c|}{ Highest Education } \\
\hline & $<$ High School & 1 & .6 \\
\hline & HS Diploma/GED & 8 & 4.8 \\
\hline & Some College & 29 & 17.3 \\
\hline & Associate's Degree & 16 & 9.5 \\
\hline & Bachelor's Degree & 64 & 38.1 \\
\hline & Master's Degree & 39 & 23.2 \\
\hline & Doctorate or Above & 11 & 6.5 \\
\hline \multicolumn{4}{|c|}{ Primary Feeding } \\
\hline & Breast & 139 & 82.7 \\
\hline & Bottle & 10 & 6.0 \\
\hline & Combination & 19 & 11.3 \\
\hline
\end{tabular}


Table 2

Demographics of Participants

Continuous Variables $(n=168)$

\begin{tabular}{lcr} 
Characteristics & Median & Range \\
\hline Age & 31 & $20-44$ \\
Number of Prior Births & 1 & $0-7$ \\
Gestational Age in Weeks & 40 & $32-44$ \\
\hline
\end{tabular}

Several of the categorical variables, as seen in Table 1, came out to very low percentages, which could potentially have had an impact on the accuracy of the analyses. Field (2009) warned against the detriment of having too many levels of a categorical variable, and suggested that a minimum of $20 \%$ of the overall sample should be represented in each level of the categorical variable. For this reason, several of the categories were combined, raising each category above the recommended $20 \%$. In the category of "Race," several of the sub-categories were combined to make up a "nonWhite" category. These include: "African American," "Asian," "Hispanic," "Pacific Islander," and "Other." In the category of "Place of Birth," the sub-categories of "Home," "Birthing Center," and "other" were combined to make up the sub-category "Out of Hospital." In the "Mode of Infant Feeding" category, "Bottle" and "Combination" were combined, to form a new sub-category of "Other", with "Breastfeeding" remaining as the other sub-category. Under "Mode of Delivery", there are now two categories: "Vaginal Birth" which is a combination of "Vaginal" and "VBAC"; and "Cesarean," made up of "Planned Cesarean" and "Unplanned Cesarean." In the "Highest Education Completed" category, "less than high school," "high school or GED" and "some college" were combined to form a new sub-category of "no college degree"; whereas "associate's 
degree" and "bachelor's degree" were combined to form the sub-category "College degree"; and finally "master's degree" and "doctorate or higher" were combined to form the sub-category "Graduate degree." The category of "Partner Status" was left as it was, as there were no options for combining sub-categories. All categorical variables were then dummy coded, as detailed in chapter 3 and the regression analysis was performed with these changes to the categorical variables, which equaled eleven variables, when added to the TES-B score, as well as the continuous variables of age, number of prior births, and gestational weeks at time of delivery. See Table 3 for the revised demographic characteristics with the combined categorical variables, their frequency and percentages.

Table 3

Combined Levels of Categorical Variables ( $n=168)$

\begin{tabular}{|c|c|c|c|}
\hline Characteristic & & Frequency & Percent \\
\hline \multicolumn{4}{|l|}{ Place of birth } \\
\hline & Hospital & 112 & 66.7 \\
\hline & Out of Hospital & 56 & 33.3 \\
\hline \multicolumn{4}{|c|}{ Mode of delivery } \\
\hline & Cesarean Section & 46 & 27.4 \\
\hline & Vaginal Birth & 122 & 72.6 \\
\hline \multicolumn{4}{|l|}{ Race } \\
\hline & White & 158 & 94.0 \\
\hline & Non-White & 10 & 6.0 \\
\hline \multicolumn{4}{|l|}{ Partner Status } \\
\hline & Single & 4 & 2.4 \\
\hline & Partnered & 164 & 97.6 \\
\hline \multicolumn{4}{|c|}{ Highest Education } \\
\hline & No College Degree & 38 & 22.6 \\
\hline & College Degree & 80 & 47.6 \\
\hline & Graduate Degree & 50 & 29.8 \\
\hline \multicolumn{4}{|c|}{ Primary Feeding } \\
\hline & Breastfeeding & 139 & 82.7 \\
\hline & Other & 29 & 17.3 \\
\hline
\end{tabular}


Trauma as measured by the Traumatic Events Scale - Form B (TES-B) had a mean score of 1.60 (Range $=1$ to $3.76, S D=0.68)$. The criterion variable, maternal self-efficacy as measured on the Parenting Sense of Competence Scale (PSOC), had a mean of $4.36($ Range $=1.69$ to $5.94, S D=0.83)$. The criterion variable, maternal appraisal of infant temperament, was measured using the Infant Behavior Questionnaire - Revised (IBQ-R). Appraisal of infant temperament had a mean of 4.70 (Range $=2.34$ to $6.03, S D=0.64$ ). Means and standard deviations for the predictor variable, trauma, and the two criterion variables, maternal self-efficacy and appraisal of infant temperament are shown in Table 4.

Table 4 Descriptive Statistics of Dependent and Independent Variables $\underline{(n=168)}$ Mean SD Trauma $^{b}$ 1.60 0.68 Maternal Self-Efficacy ${ }^{a}$ 4.36 0.83 Appraisal of Infant Temperament ${ }^{a}$ 4.70 0.64

\footnotetext{
${ }^{\mathrm{a}}$ criterion variable

${ }^{\mathrm{b}}$ predictor variable
}

\section{Results of Data Analysis}

A backward stepwise regression method was employed to test the research hypotheses. Hypothesis 1: It is expected that an inverse relationship will be found between the predictor variable, a participant's score on a measure of childbirth-related trauma (TES-B) and the criterion, her score on the Parenting Sense of Competency Scale (PSOC), a measure of parenting self-efficacy. An individual's score on the TES-B will serve as a significant predictor of her score on the PSOC. Individuals with higher 
scores on the trauma measure will exhibit significantly lower parental self-efficacy scores than those with lower scores on the TES-B.

Hypothesis 2: It is expected that an inverse relationship will be found between the predictor variable, a participant's score on a measure of childbirth-related trauma (TESB) and the criterion, her score on the Infant Behavior Questionnaire-Revised (IBQ-R), a measure of infant temperament appraisal. An individual's score on the TES-B will serve as a significant predictor of her score on the IBQ-R. Individuals with higher scores on the trauma measure will get lower scores on the IBQ-R, which represents a more negative perception of the infant's temperament.

Data Analysis for Predicting Maternal Self-Efficacy. The demographic predictor variables, along with the participants' TES-B scores were entered into the SPSS program in a backward stepwise method, using the criteria of "greater than or equal to $5 \%$ " explained variance to enter and "less than or equal to" $10 \%$ to remove and regressed onto the participants' PSOC score. In examining the model summary, the first model, which included all twelve predictor variables had an $R^{2}$ value of .376, meaning that $37.6 \%$ of the variability in the outcome is accounted for by the twelve predictors. As variables continued to be removed from the analyses, based on their not meeting inclusion criteria, the final model is left with an $\mathrm{R}^{2}$ value of .347 , or $34.7 \%$ of the variability in the outcome is accounted for by a single variable, the participant's TES-B score. Also, in looking at the adjusted $\mathrm{R}^{2}$ for each of the models in the analysis and comparing them to the $\mathrm{R}^{2}$ values, they are quite discrepant in the first several models, indicating that the model is not very easily generalizable. However, in looking at the final model, with an $R^{2}$ to adjusted $R^{2}$ difference of 0.04 , this shrinkage indicates that if 
the model were derived from the population rather than a sample, it would account for approximately $.4 \%$ less variance. The Model Summary for the PSOC regression analysis can be seen in Table 5 .

Table 5

Model Summary for Backward Stepwise Regression onto PSOC

\begin{tabular}{lccrrr}
\hline Model & $\mathrm{R}$ & $\mathrm{R}^{2}$ & Adjusted $\mathrm{R}^{2}$ & SE & Durbin-Watson \\
\hline 1 & $.613^{\mathrm{a}}$ & .376 & .332 & .67786 & \\
2 & $.613^{\mathrm{b}}$ & .376 & .337 & .67570 \\
3 & $.613^{\mathrm{c}}$ & .376 & .341 & .67358 \\
4 & $.613^{\mathrm{d}}$ & .376 & .345 & .67163 \\
5 & $.612^{\mathrm{e}}$ & .374 & .347 & .67031 \\
6 & $.611^{\mathrm{f}}$ & .373 & .350 & .66890 \\
7 & $.609^{\mathrm{g}}$ & .371 & .351 & .66819 \\
8 & $.606^{\mathrm{h}}$ & .367 & .351 & .66807 \\
9 & $.603^{\mathrm{i}}$ & .363 & .352 & .66802 \\
10 & $.596^{\mathrm{j}}$ & .355 & .347 & .67011 & \\
11 & $.589^{\mathrm{k}}$ & .347 & .343 & .67230 & \\
\hline
\end{tabular}

a. Predictors: (Constant), Number of prior births (NOT including this most recent one):Select number, Gestational age in weeks at time of delivery:-Select age, Partner_Code, VB, GradDeg, Breast, White, NoCollDeg, Hospital, Your Age: -Select your age, Ave_TES

b. Predictors: (Constant), Number of prior births (NOT including this most recent one):Select number, Gestational age in weeks at time of delivery:-Select age, Partner_Code, VB, GradDeg, Breast, White, Hospital, Your Age: -Select your age, Ave_TES

c. Predictors: (Constant), Number of prior births (NOT including this most recent one):Select number, Gestational age in weeks at time of delivery:-Select age, Partner_Code, VB, GradDeg, White, Hospital, Your Age: -Select your age, Ave_TES

d. Predictors: (Constant), Number of prior births (NOT including this most recent one):Select number, Gestational age in weeks at time of delivery:-Select age, Partner_Code, VB, White, Hospital, Your Age: -Select your age, Ave_TES

e. Predictors: (Constant), Number of prior births (NOT including this most recent one):Select number, Gestational age in weeks at time of delivery:-Select age, Partner_Code, VB, White, Your Age: -Select your age, Ave_TES

f. Predictors: (Constant), Number of prior births (NOT including this most recent one):-

Select number, Gestational age in weeks at time of delivery:-Select age, Partner_Code, VB, White, Ave_TES

g. Predictors: (Constant), Number of prior births (NOT including this most recent one):Select number, Gestational age in weeks at time of delivery:-Select age, VB, White, Ave_TES 
h. Predictors: (Constant), Gestational age in weeks at time of delivery:-Select age, VB, White, Ave_TES

i. Predictors: (Constant), VB, White, Ave_TES

j. Predictors: (Constant), White, Ave_TES

k. Predictors: (Constant), Ave_TES

As the backward stepwise regression analysis eliminated variables based upon the inclusion / exclusion criteria, the final model was left with one variable which is a significant predictor of PSOC score, and that is TES-B score. The standardized $b$-value of the participants' TES-B score (standardized $\beta=-0.589$ ) tells the number of standard deviations that the outcome will change as a result of one standard deviation change in the predictor. So in this regression model, as the participant's TES-B score increases by one standard deviation, her PSOC score will decrease by -0.589 standard deviations. More specifically, as a participant's trauma score increases by .68 , the maternal self-efficacy score will decrease by $.49(-.589 \times .83)$. The $t$-statistic is able to tell whether a $\beta$ value is significantly different from zero, and therefore is making a significant contribution to the model. The smaller the $p$ value, and the larger the $t$ value, the greater is the contribution to the predictive value of the model. In this case the regression model indicated that the participant's trauma score was a significant predictor of her maternal self-efficacy score $(t=-9.395, p<.001)$. The results of the final model can be seen in Table 6 .

Table 6

Coefficients of significant model PSOC

\begin{tabular}{|c|c|c|c|c|c|c|}
\hline \multirow[b]{2}{*}{ Model } & & \multicolumn{2}{|c|}{$\begin{array}{c}\text { Unstandardized } \\
\text { Coefficients }\end{array}$} & \multicolumn{3}{|l|}{$\begin{array}{l}\text { Standardized } \\
\text { Coefficients }\end{array}$} \\
\hline & & $\mathrm{B}$ & SE & $\beta$ & $\mathrm{t}$ & $p$ \\
\hline \multirow[t]{2}{*}{9} & (Constant) & 5.511 & .133 & & 14.495 & .000 \\
\hline & Trauma & -.719 & .077 & -.589 & -9.395 & .000 \\
\hline
\end{tabular}


Hypothesis 1 therefore, is supported, meaning that individuals with higher scores on the trauma measure will exhibit significantly lower parental self-efficacy scores than those with lower scores on the TES-B.

Testing Assumptions for the PSOC Regression Model

Regression diagnostics were performed to test the assumptions of the model.

The assumption of normality is tested by examining the standardized residuals to make sure that they are normally distributed. This was done through visually inspecting the data, examining SPSS estimates of skewness and kurtosis, as well as performing Kolmogorov-Smirnov and Shapiro-Wilks tests through SPSS. The skewness and kurtosis should be between $-/+1$ to pass the test of normality, and in this model they are at -.158 and -.059 , respectively. When looking at the Kolmogorov-Smirnov and Shapiro-Wilks tests of normality, the $p$ value should be $>.05$ and in this instance they are at $p=.200$ and $p=.600$, respectively; therefore, the assumption of normality is met. The test statistics for normality can be found in Table 7 .

Table 7: Normality Statistics ${ }^{a}$

\begin{tabular}{llccc}
\hline & & & & \\
& & Statistic & SE & \multicolumn{2}{c}{ Sig. } \\
\hline Standardized Residual & Skewness & -.158 & .187 & \\
& Kurtosis & -.059 & .373 & \\
& Kolmogorov-Smirnov & .053 & & .200 \\
& Shapiro-Wilks & .993 & & .600 \\
\hline${ }^{a}$ Variable: PSOC & & & &
\end{tabular}

Cook's distance and Mahalanobis are approaches used to detect outliers.

Cook's distance evaluates whether an individual outlier appears to be having undue influence on the regression model and a value greater than 1 indicates that it appears to have significant influence. In the current model, the Cook's distance value of 0.008 in 
the current model suggests that no individual case appears to have too great an influence on the regression model. Likewise, Mahalanobis distance accounts for the variance of each variable and covariance between variables. Mahalanobis distance $>15$ is cause for concern. In the present model, the Mahalanobis distance value of .994 is well within the acceptable range.

Homoscedasticity is the assumption that the variance of errors is the same across all levels of the independent variable. In examining the plots of the standardized residuals against the standardized predictor in this analysis, it appears to show little to no correlation in data and the assumption of homoscedasticity does not appear to be violated. The Durbin-Watson statistic tests for the intercorrelation of the variables and whether the assumption of independence of errors is upheld. The Durbin-Watson value should be at or near 2, and as seen in Table 5 , the value is 2.135 in this regression model, suggesting that the assumption of serial independence of errors has been met.

The next assumption that was tested is multicollinearity, meaning that there is no highly linear relationship between any of the independent variables. One way of testing this assumption is by looking at the Variation Inflation Factor (VIF) to see that it is $<10$ and also insuring that the tolerance is $>0.1$. In the current model, the tolerance for was .956 and the VIF 1.00. As seen in Table 10 below, multicollinearity does not appear to be an issue with this regression model.

Data Analysis for Predicting Appraisal of Infant Temperament. The same dichotomous demographic predictor variables used in the previous analysis, along with the participants' TES-B scores were entered into the SPSS program in a backward stepwise method, using the criteria of "greater than or equal to 5\%" explained variance 
to enter and "less than or equal to" $10 \%$ to remove and were regressed on the participants' IBQ-R score.

In examining the model summary, the first model, which included all predictor variables had an $R^{2}$ value of .283 , meaning that $28.3 \%$ of the variability in the outcome is accounted for by the predictors. As variables continued to be removed from the analyses, based on their not meeting inclusion criteria, the final model is left with an $\mathrm{R}^{2}$ value of .255 , or $25.5 \%$ of the variability in the outcome is accounted for by the remaining variables, the participant's TES-B score, gestational age in weeks at time of delivery, and white race. Also, in looking at the adjusted $R^{2}$ for each of the models in the analysis and comparing them to the $\mathrm{R}^{2}$ values, they are quite discrepant in the first several models, indicating that the model is not very easily generalizable. However, in looking at the final model, with an $R^{2}$ to adjusted $R^{2}$ difference of 0.1 , this shrinkage indicates that if the model were derived from the population rather than a sample, it would account for approximately .1\% less variance. The Model Summary for the PSOC regression analysis can be seen in Table 8.

Table 8

Model Summary for Backward Stepwise Regression onto IBQ-R

\begin{tabular}{lrrrrr} 
Model & $\mathrm{R}$ & $\mathrm{R}^{2}$ & Adjusted $\mathrm{R}^{2}$ & SE & Durbin-Watson \\
\hline 1 & $.532^{\mathrm{a}}$ & .283 & .232 & .56515 & \\
2 & $.532^{\mathrm{b}}$ & .283 & .237 & .56335 & \\
3 & $.532^{\mathrm{c}}$ & .283 & .242 & .56163 \\
4 & $.531^{\mathrm{d}}$ & .282 & .246 & .55993 \\
5 & $.529^{\mathrm{e}}$ & .279 & .248 & .55934 \\
6 & $.524^{\mathrm{f}}$ & .274 & .247 & .55949 \\
7 & $.520^{\mathrm{g}}$ & .270 & .247 & .55949 \\
8 & $.514^{\mathrm{h}}$ & .264 & .246 & .55989 & \\
9 & $.505^{\mathrm{i}}$ & .255 & .241 & .56175 &
\end{tabular}




\section{CHILDBIRTH-RELATED TRAUMA 64}

a. Predictors: (Constant), Number of prior births (NOT including this most recent one):-Select number, Gestational age in weeks at time of delivery:-Select age, Partner_Code, VB, GradDeg, Breast, White, NoCollDeg, Hospital, Your Age: -Select your age, Ave_TES b. Predictors: (Constant), Number of prior births (NOT including this most recent one):-Select number, Gestational age in weeks at time of delivery:-Select age, VB, GradDeg, Breast, White, NoCollDeg, Hospital, Your Age: -Select your age, Ave_TES

c. Predictors: (Constant), Number of prior births (NOT including this most recent one):-Select number, Gestational age in weeks at time of delivery:-Select age, VB, GradDeg, White, NoCollDeg, Hospital, Your Age: -Select your age, Ave_TES

d. Predictors: (Constant), Number of prior births (NOT including this most recent one):-Select number, Gestational age in weeks at time of delivery:-Select age, GradDeg, White,

NoCollDeg, Hospital, Your Age: -Select your age, Ave_TES

e. Predictors: (Constant), Number of prior births (NOT including this most recent one):-Select number, Gestational age in weeks at time of delivery:-Select age, GradDeg, White,

NoCollDeg, Your Age: -Select your age, Ave_TES

f. Predictors: (Constant), Number of prior births (NOT including this most recent one):-Select number, Gestational age in weeks at time of delivery:-Select age, White, NoCollDeg, Your

Age: -Select your age, Ave_TES

g. Predictors: (Constant), Number of prior births (NOT including this most recent one):-Select number, Gestational age in weeks at time of delivery:-Select age, White, NoCollDeg,

Ave_TES

h. Predictors: (Constant), Gestational age in weeks at time of delivery:-Select age, White, NoCollDeg, Ave_TES

i. Predictors: (Constant), Gestational age in weeks at time of delivery:-Select age, White, Ave_TES 
As the backward stepwise regression analysis eliminated variables based upon the inclusion / exclusion criteria, the final model was left with three variables which were significant predictors of IBQ-R score: TES-B score, gestational age at time of delivery, and white race. The standardized $\beta$-values were as follows: TES-B score (standardized $\beta$ $=-0.454)$, gestational age at time of delivery $(\beta=.194)$ and white race $(\beta=.117)$. This describes the number of standard deviations that the outcome will change as a result of one standard deviation change in the predictor. So in this regression model, as the participant's TES-B score increases by one standard deviation, her IBQ-R score will decrease by -0.454 standard deviations. More specifically, as the participant's trauma score increases by .68 , the infant temperament score will decrease by $.29(-.454 \times .64)$.. The t-statistic is able to tell whether a $\beta$ value is significantly different from zero, and therefore is making a significant contribution to the model. The smaller the value of $p$, and the larger the value of $t$, the greater is the contribution to the predictive value of the model. In this case the regression model indicated that the participant's trauma score was a significant predictor of her infant temperament score $(\mathrm{t}=-6.59, p<.001)$, as was the gestational age in weeks at time of delivery $(\mathrm{t}=2.85, p<.05)$. The third variable, white race, was also approaching significance $(\mathrm{t}=1.71, p<.09)$. The results of the final model can be seen in Table 9.

\begin{tabular}{|c|c|c|c|c|c|c|}
\hline \multirow[b]{2}{*}{ Model } & & \multicolumn{2}{|c|}{$\begin{array}{c}\text { Unstandardized } \\
\text { Coefficients }\end{array}$} & \multicolumn{3}{|l|}{$\begin{array}{l}\text { Standardized } \\
\text { Coefficients }\end{array}$} \\
\hline & & $\mathrm{B}$ & SE & $\beta$ & $t$ & $p$ \\
\hline \multirow[t]{4}{*}{9} & (Constant) & 2.574 & .897 & & 2.869 & .005 \\
\hline & Trauma & -.431 & .065 & -.454 & -6.586 & .000 \\
\hline & White & .318 & .186 & .117 & 1.708 & .090 \\
\hline & Gestational age in weeks at time of delivery & .063 & .022 & .194 & 2.854 & .005 \\
\hline
\end{tabular}


Hypothesis 2 therefore, is supported, meaning that individuals with higher scores on the trauma measure will exhibit significantly lower scores on appraisal of their infant's temperament than those with lower scores on the TES-B. Testing Assumptions for the IBQ-R Regression Model

Regression diagnostics were performed to test the assumptions of the model. The assumption of normality is tested by examining the standardized residuals to make sure that they are normally distributed. This was done through visually inspecting the data, examining SPSS estimates of skewness and kurtosis, as well as performing Kolmogorov-Smirnov and Shapiro-Wilks tests through SPSS. The skewness and kurtosis should be between $-/+1$ to pass the test of normality, and in this model they are at -.079 and -.104 , respectively. When looking at the Kolmogorov-Smirnov and Shapiro-Wilks tests of normality, the $p$ value should be $>.05$ and in this instance they are at $p=.200$ and $p=.479$, respectively; therefore, the assumption of normality is met. The test statistics for normality can be found in Table 10 .

Cook's distance and Mahalanobis are approaches used to detect outliers. Cook's distance evaluates whether an individual outlier appears to be having undue influence on the regression model and a value greater than 1 indicates that it appears to having significant influence. In the current model, the Cook's distance value of 0.10 in the current model suggests that no individual case appears to have too great an influence on the regression model. Likewise, Mahalanobis distance accounts for the variance of each variable and covariance between variables. Mahalanobis distance $>15$ 
is cause for concern. In the present model, the Mahalanobis distance value of 2.98 is well within the acceptable range.

Table 10

Normality Statistics ${ }^{a}$

\begin{tabular}{llrrr} 
& & Statistic & SE & Sig. \\
\hline Standardized Residual & Skewness & -.08 & .187 & \\
& Kurtosis & -.10 & .373 & .200 \\
& Kolmogorov-Smirnov & .43 & & .479 \\
\hline
\end{tabular}

${ }^{\mathrm{a}}$ Variable: IBQ-R

Homoscedasticity is the assumption that the variance of errors is the same across all levels of the independent variable. In examining the plots of the standardized residuals against the standardized predictor in this analysis, it appears to show little to no correlation in data and the assumption of homoscedasticity does not appear to be violated. The Durbin-Watson statistic tests for the intercorrelation of the variables and whether the assumption of independence of errors is upheld. The Durbin-Watson value should be at or near 2, and as seen in Table 7, the value is 2.047 in this regression model, suggesting that the assumption of serial errors has been met.

The next assumption that will be tested is multicollinearity, meaning that there is no highly linear relationship between any of the independent variables. One way of testing this assumption is by looking at the VIF (variation inflation factor) to see that it is $<10$ and also insuring that the tolerance is $>0.1$. As seen in Table 10 below, multicollinearity does not appear to be an issue with this regression model. 
Table 11:

Collinearity Statistics

\begin{tabular}{lcr} 
Model & Tolerance & VIF \\
\hline (Constant) & & 1.046 \\
Trauma & .956 & 1.033 \\
White race & .968 & 1.013 \\
Gestational age in weeks & .987 & \\
at time of delivery & &
\end{tabular}

a. Dependent Variable: IBQ-R

In the Casewise Diagnostics table, SPSS identified 6 outliers which may have undue influence on the outcome variable, but upon closer inspection, only one of these outliers was more than three standard deviations from the mean. 


\section{CHAPTER 5: Discussion}

For nearly two decades, the empirical literature has focused on prevalence and predictors of posttraumatic stress following childbirth, as well as some of the short- and long-term effects of traumatic birth. However, there have been very few studies examining the effects of childbirth-related posttraumatic stress on a woman's maternal self-efficacy, and her perception of her infant's temperament.

Following childbirth, studies have reported that between $20 \%$ and $38 \%$ of women rate their experience of birth as traumatic (Alcorn, O'Donovan, Patrick, Creedy, \& Devilly, 2010; Ayers, Harris, Sawyer, Parfitt, \& Ford, 2009; Creedy, Shochet, \& Horsfall, 2000; Soet, Brack, \& Dilorio, 2003). In line with previous research, $20.2 \%$ of participants in the present study rated their births as 'somewhat' to 'very much' traumatic. While in the range of previous studies, there are some potential reasons why the rate of trauma in this study fell at the low end of what had been reported in prior research. Several prior studies (Soet, et al., 2003; Ford \& Ayers, 2011; Creedy, Shochet, \& Horsfall, 2000) found certain variables to be significantly associated with posttraumatic stress symptoms, including cesarean birth, not breastfeeding as long as desired, and obstetric intervention during the labor and delivery. In the present study, these particular groups seem to have been underrepresented. Approximately $27.4 \%$ of respondents delivered by Cesarean vs. $36 \%$ in the general US population; $94 \%$ of respondents in the current study were breastfeeding vs. rates in the general population of $72.9 \%$ having ever breastfed their babies. Perhaps most noteworthy, $33.4 \%$ of participants in the present study gave birth in an out-of-hospital setting as compared to approximately $2 \%$ of the general US population which, by default would lead to less 
obstetric intervention. These factors may explain why the percentage of women reporting trauma was lower in this study than in other studies with more representative samples. This is likely due to the online recruitment sources, several of which were midwifery-related websites, and may thereby be frequented by mothers in these specific demographic categories. While there was also recruitment from websites geared toward individuals suffering from childbirth-related trauma, there was no tally to indicate which of the websites participants were recruited from, so it is possible that those who were most affected by trauma either opted out of participating or began the survey, but did not complete it, resulting in incomplete (and thereby, unusable) data.

\section{Childbirth-related trauma and parenting self-efficacy}

The first objective of this study was to examine the prevalence of childbirthrelated trauma and its effect on maternal self-efficacy in women who were between 3 and 12 months postpartum. It was hypothesized that an inverse relationship would be found between the predictor variable, a participant's score on a measure of childbirthrelated trauma (TES-B) and the criterion, her score on the Parenting Sense of Competency Scale (PSOC), a measure of parenting self-efficacy. Individuals with higher scores on the trauma measure were expected to exhibit significantly lower parental self-efficacy scores than those with lower scores on the TES-B. The data supported this hypothesis and it appears to be an extension of prior research on childbirth trauma, as well as research into low parenting self-efficacy. Whittaker and Cowley (2012) reported that "lower self-efficacy scores correlated with high ratings for 'feeling tired' and 'receiving negative comments,'” both of which are themes reported in 
other studies concerning both parenting self-efficacy and childbirth-related posttraumatic stress (Coleman \& Karraker, 2000; Creedy, et al., 2000).

Although research into parental fatigue is relatively recent, studies indicate that fatigue is associated with low parenting self-efficacy (PSE), and parenting behaviors such as low warmth and high irritability during parent-child interactions (Cooklin, Giallo, \& Rose, 2011; Dunning \& Giallo, 2012). While participants in the current study were not asked to evaluate their fatigue levels, birth trauma, complications, and difficult recovery process have been linked to increased fatigue (Ansara, Cohen, Gallop, Kung, \& Schei, 2005); therefore, women who have experienced birth trauma are prime candidates for experiencing extreme fatigue following their births, thus putting them at risk for decreased parental self-efficacy. Furthermore, while not specifically asked about in the present study, poor nutrition in the postnatal period (Lee \& Zaffke, 1999), negligent selfcare behaviors (Giallo, Rose, \& Vittorino, 2011), and the inability to self-regulate (Baumeister \& Vohs, 2007), are all potential explanations of parent fatigue, the very same behaviors often expressed by individuals recovering from trauma.

Prevention of childbirth-related trauma is the ideal, because as Cheryl Beck, a prominent researcher in the field of birth trauma, has described, "Mothers with posttraumatic stress disorder attributable to childbirth struggle to survive each day while battling terrifying nightmares and flashbacks of the birth, anger, anxiety, depression, fatigue and painful isolation from the world of motherhood..." (2004, p.222). The present study adds two more consequences to the list of difficulties: low maternal selfefficacy and negative appraisal of infant temperament. In many instances of PTSD, the sufferer may avoid experiencing daily reminders of the traumatic event in such a 
present way as in this particular situation, where the woman is expected to interact with, provide care for, and remain positive and nurturing to her infant, a very real and vivid reminder of the traumatic experience. These symptoms of flashbacks, nightmares, anxiety, depression, and anger can then serve to further diminish the woman's parenting self-efficacy, and make her view her infant in an even more negative light. It would be valuable in future research to implement treatment for the posttraumatic stress and to re-evaluate the self-efficacy and infant temperament at a predetermined date, well into treatment to see if, as the trauma scores began to decrease as a result of treatment, the self-efficacy scores and infant temperament changed as well, or if these were somehow solidified early on in the course of the trauma.

\section{Demographic variables and parenting self-efficacy}

Perhaps not surprisingly, the demographic factors evaluated in this study did not appear to play a role in maternal self-efficacy. Other studies have garnered similar results in regards to several of the demographic characteristics examined in the present study. Specifically in regards to gestational age as a determinant of maternal selfefficacy, Pennell, Whittingham, Boyd, Sanders, and Colditz (2012) discovered that "Contrary to expectations, parents of very preterm infants did not report significantly lower overall levels of parental self-efficacy or significantly higher levels of psychological symptoms compared to parents of preterm and term infants" (p.678). On a broader scale of examining demographic factors as potential predictors, Sevigny and Loutzenhizer (2009) concluded that general self-efficacy was the only personal variable to emerge as a statistically significant predictor of PSE. A previous study of mothers and 
their school-aged children found a similar result, that demographic factors were not significantly associated with maternal self-efficacy (Coleman \& Karraker 2000).

There are several potential reasons why demographics information does not appear to play a role in parenting self-efficacy of the participants of this study. There was a notable homogeneity among the participants, with regard to race, partner status, education level, parity, and primary mode of feeding. It is possible that significant predictors did not emerge due to this lack of diversity. For future studies, different sampling methods would need to be employed to increase the chances of gaining a more representative sample. However, from a biopsychosocial standpoint, it is probable that these particular groups of women may be more likely to participate in studies such as this one, and future studies may need to consider incentives to encourage participation from a more varied demographic sample. Another reason why demographic information did not turn up as a significant predictor of parenting selfefficacy is the very nature of self-efficacy and the factors which affect self-efficacy (e.g., prior mastery experiences, prior vicarious experiences, social persuasion) are not particularly tied to the demographic variables utilized in the present study. Questions regarding social support, history of feeling successful, etc. may provide more usefulness in future research.

Certain aspects of the findings were in contrast to previous studies on selfefficacy. For example, Salonen et al. (2009) reported that parity (number of prior births) was predictive of parenting self-efficacy, whereas in the present study there were no significant differences found in parenting self-efficacy scores between first time mothers and mothers who had older children. This came as somewhat of a surprise because, in 
general, women who already have older children are often viewed as "settled in" or "at ease" in the mothering role than first time mothers whose every experience with mothering is a novel one. Future research should consider comparing groups of participants, labeled "trauma" versus "non-trauma," and then examine whether parity played a role in parental self-efficacy in those women who had experienced birth trauma versus those women who had not, which would explain whether or not birth trauma has a mediating effect between parity and parental self-efficacy.

\section{Childbirth-related trauma and appraisal of infant temperament}

The second objective in this study was to examine the prevalence of childbirthrelated trauma and its effect on appraisal of infant temperament. It was hypothesized that an inverse relationship would be found between the predictor variable, a participant's score on a measure of childbirth-related trauma (TES-B) and the criterion, her score on the Infant Behavior Questionnaire-Revised (IBQ-R), a measure of infant temperament appraisal. Individuals with higher scores on the trauma measure were expected to have lower scores on the IBQ-R, which represents a more negative perception of the infant's temperament. The study found significant results in support of this hypothesis as well, which falls in line with what other researchers have discovered regarding perception of infant temperament.

Huizink et al. (2002) reported that mother's postnatal stress experience correlated with less positive perceptions of the infant temperament, even after controlling for her prenatal stress level. As cited in several childbirth-related trauma studies, mothers who have experienced a traumatic birth report higher levels of stress in the postpartum period (Alders et al., 2006; Ayers et al., 2009, Ayers et al., 2007), which 
would result in these women rating their infants' temperaments more negatively. Furthermore, Kingston, Tough and Whitfield (2012), summarize that, "This review provides evidence of an effect of postpartum psychological distress on infant development (e.g., socio-emotional and cognitive), and it also demonstrates that prenatal distress can have detrimental effects on an infant's cognitive, psychomotor, and behavioral development" (p. 707). The primary reason why this finding is so important as one aspect in the bigger scheme of things is because that early infant temperament, or perhaps more accurately, maternal appraisal of infant temperament, can begin to shape how that individual's self-perception, self-esteem, and world view as s/he develops into a toddler, young child, adolescent, and throughout the course of his/her life. In this way, unresolved traumatic birth experience can be viewed as a multigenerational problem, with potential to perpetuate dysfunction not only in the mother who experienced the traumatic birth, but in the infant as well.

\section{Demographic variables and appraisal of infant temperament}

In addition to the participants' trauma scores being predictive of maternal appraisal of infant temperament, so also was the demographic variable "gestational age in weeks at time of delivery," with the younger the infant in weeks, the more negatively appraised was the temperament. Building upon previous research, it is possible that this more negative evaluation of infant temperament is due to the increased parenting stress that goes along with having a preterm infant. Voeghtline and Stifter (2010) concluded that late-preterm status predicted higher ratings of infant negativity by mothers. Similarly, Gray, Edwards, O'Callaghan, Cuskelly and Gibbons (2013) reported that "For the preterm group [as compared to the term infants], maternal 
depression and infant temperament were predictors of Total Stress scores on multivariate analysis" (p.625). In the model prior to the final model, the variable of White Race was approaching significance, as seen in the results section of this document.

Due to the fact that this variable was extremely homogeneous ( $94 \%$ of participants were white), it may be valuable for future research to replicate the study using a more diverse sample to see whether the variable of race does, in fact, appear to be a significant predictor of infant temperament appraisal.

\section{Limitations}

There are limitations of the research in the present study. One limitation is the representativeness of the sample. When compared to the general population of birthing women in the United States, the sample in the present study over represents white, highly educated, partnered, breastfeeding mothers who had vaginal births in an out-ofhospital setting. I believe the reason for this is two-fold. First, because the recruitment letter for the study was posted on midwifery-related sites, it may have been seen by and responded to by more out-of-hospital birthers, whose demographic in the US is that of older, white, more highly educated, partnered, breastfeeding mothers. While the recruitment letter was also posted on birth trauma-related sites, as well as the International Cesarean Awareness Network site, it is possible that women who were currently in the throes of posttraumatic trauma symptomatology did not have the motivation to complete the surveys. Secondly, and along these same lines, 220 women began the surveys, while only 168 completed them, for a response rate of $76.3 \%$. It is possible that the surveys may have been more likely to be too cumbersome and/or emotionally intense for those women who had experienced trauma, as well as the 
respondents with less education, single status, or who had surgical deliveries. More population-based research is needed to further explore rates of trauma and to explore differences between different demographic groups.

Furthermore, because the recruitment was done completely online, it is difficult to know whether the sample was comprised wholly of American women, or whether it represented a more internationally diverse sampling. It is thought that the sample is more than likely comprised of US women, as the recruitment was done completely through US-based and primarily US-utilized websites. Because of this, it is hard to say whether the results are generalizable to the population of birthing women as a whole in the United States, and on a grander scale to birthing women internationally.

Another limitation is that some potentially important confounding variables may have been omitted from the demographic variable survey, in the interest of brevity. Previous studies have linked lack of social support, prior mental health treatment, and instrumental vaginal delivery to posttraumatic stress symptoms. The social support factor is probably of the most importance, wherein a woman's social support may reflect the environment in which she is attempting to recover from the childbirth-related trauma, and could have an impact on both her self-efficacy and her perception of her infant's temperament. Because none of these were included in the present study, it is unknown as to whether or not they may have had some effect on the multiple linear regression equation in the backward stepwise process.

The study design may also predispose itself to inherent biases due to the nature of data collection. Participants completed self-report questionnaires, and with this type of data collection there is the risk of social desirability or skewed self-perception 
interfering with the integrity of the responses. Women who are newly postpartum often experience strong societal pressure to be happy or to present themselves as happy with their birth experience, as a way of putting their newborn's needs ahead of their own. So, while confidentiality and anonymity were carefully spelled out in the informed consent, it may not have prevented participants from responding in a way that is perceived as socially desirable.

\section{Clinical Implications and Direction for Future Research}

This study provides medical and mental health professionals with valuable information about the relationships among childbirth-related posttraumatic stress, parenting self-efficacy and infant temperament. Based upon the significant findings of the present study, recommendations can be made for clinical interventions, as well as future research. The following provides an overview of these findings and the implications related to the study results.

Clinically, there are several points in which providers may be able to intervene, based upon the results of several recent studies (Alder et al. 2008; Anderson, Melvaer, Videbech, Lamont, and Joergensen, 2012; Ayers et al., 2008; Ayers et al., 2006; Ayers et al., 2004; Ayers, and Warren, 2011; Harvey et al., 2003; Meades, Pond, PerezBlasco, Rowan et al., 2007; Verreault et al., 2012; Viguer, and Rodrigo, 2013; and Whittaker and Cowley, 2012). I have synthesized the relevant findings in Figure 3. First and perhaps most sensibly, would be attempting to prevent or minimize the trauma response, either prenatally, during the birth itself, or in the immediate postpartum. We know from prior research what many of the predisposing factors are for a woman to experience a traumatic birth, including lack of social support, history of sexual trauma, 
prior mental health treatment, distress in labor, obstetrical emergencies, and perceived lack of support during the delivery process (Andersen, et al., 2012; Ayers, et al., 2008; and Verreault et al., 2012). From this, an important step is taking a detailed history during the pregnancy, including inquiry into each woman's mental health history, past sexual trauma, and perceived social support. Additionally, medical personnel may need to consider the physical and psychological consequences of each medical intervention, when weighing in on benefits vs. risks of administering a specific intervention. This might include detailed communication with the woman throughout the decision-making process regarding her labor and interventions. Furthermore, it may prove helpful for the care provider to discuss with the woman her expectations and ideas about the labor and delivery process prenatally. Additionally, an overview of what is known about childbirthrelated trauma could be provided to the mothers during their labor and delivery classes at the hospital. These steps, coupled with knowledge about the woman's actual course of labor and delivery afterwards, will enable identification of those women who are at high risk for developing childbirth-related PTSD.

Being able to identify those individuals who appear to be suffering from a trauma response as a result of birth, and implement a trauma treatment plan, utilizing evidencebased treatment modalities for these mothers, is imperative. Identification would involve administering a trauma inventory, such as the TES-B used in this study, to each women at the six-week postpartum visit, perhaps sooner with those women who were identified as high-risk. Those women who had indicate that they are suffering from posttraumatic stress regarding their birth would then be targeted for treatment. In terms of treatment, Meades et al. (2011) reported "symptoms reduced over time... in women who attended 
debriefing. Debriefing also led to a reduction in negative self-appraisal in many of the participants" (p.367), with similar results shown by Ayers et al. (2004). In a qualitative study in 2006, Ayers et al. found cognitive behavioral therapy (CBT) to be an effective treatment for postnatal PTSD, and Harvey et al. (2003) reported $50 \%$ to $90 \%$ of women recovering from postnatal PTSD when engaged in CBT.

The next place where intervention could take place would be controlling the aforementioned factors that have been linked to low maternal self-efficacy and low appraisal of infant temperament.

\section{Points of clinical intervention}

\section{Prevent / minimize trauma}

-Prenatally

- Intrapartum

-Postpartum

\section{Identify trauma}

- Screening tools prior to leaving hospital or birthing center

-Interview / evaluation at six-week postpartum visit with care provider

\section{Treat trauma}

- Community-based new mothers' trauma treatment group will skilled provider

- Structured de-briefing offered within the first few days following the birth

-Individual cognitive-behavioral therapy referrals with counselor trained in post-birth trauma issues

\section{Increase parental self-efficacy}

- In home services from midwife or peer counselor

- Community-based group (as described above) for modeling of mothering behaviors

- Decreasing fatigue through time management / stress management courses

\section{Increase positive appraisal of infant temperament}

- Psychoeducation regarding developmentally appropriate infant behavior

-Parent training course to assist with mother-newborn interaction

Figure 3. This figure illustrates the points of clinical intervention 
Prior research found that self-efficacy is a determinant of later behavior (Bandura, 1997). High parenting self-efficacy is important for a sense of well-being and parenting satisfaction and is also a predictor of adequate parenting practices and may be an indicator of risk (Coleman \& Karraker, 1997, Drake et al. 2007, and Elek et al. 2003). The current research in the field has reported that various interventions including mindfulness-based approaches (Perez-Blasco, et al., 2013), as well as health provider visitation and parenting support groups (Whittaker \& Cowley, 2012) may improve parenting self-efficacy in mothers.

"To maximise potential through parenting support, attention should be given to addressing factors associated with poorer self-efficacy experiences, including parental tiredness. Equally, practice should be directed at developing community environments that offer exposure to positive and the opportunity to practice new skills without facing criticism" (Whittaker \& Cowley, 2012). What this would look like in the context of this study would be identification of those women who experienced their births as traumatic, measured at their six-week postpartum visit with their provider, and then offering in home services from the midwife or peer counselor, with the aim of developing parent training skills, as well as modeling mothering behavior to these women. The second implementation would be that of a community-based new mother's trauma treatment group, where the participants would receive skilled counseling to resolve the birth trauma issues, as well as becoming connected with other new mothers, which would serve to increase self-efficacy, while decreasing trauma response.

Furthermore, the literature examining childbirth-related PTSD has demonstrated the effectiveness of numerous counseling and de-briefing interventions, implemented at 
various points in the postpartum period (Alder et al. 2006, Rowan et al. 2007). With the findings provided by the present study, clinicians may be able to identify in the postpartum period those women who have experienced birth trauma and offer effective interventions to them. Ideally, routine screening instruments could be administered to women at their six-week postpartum visit with their care provider, and those women with high scores may be referred for treatment.

Future researchers may want to make the study more generalizable to the population, by increasing the sample size and also by broadening recruitment methods to be more inclusive. Additionally, a longitudinal study following the same participants through the first two years or so postpartum may provide insight into the course of the trauma response and also changes in maternal self-efficacy and the mother's appraisal of her baby's temperament. It may also be beneficial to include more specific questions regarding demographic and obstetric variables, particularly with regards to fatigue, nutrition, and self-care, variables which have been connected with low parenting selfefficacy in previous studies, to see if any of these variables provide a moderating effect between trauma and self-efficacy.

\section{Conclusion}

The objectives of the present study were: to examine whether the incidence of traumatic birth could successfully predict a mother's self-efficacy at 3 to 12 months postpartum, and also to examine whether birth trauma could predict maternal appraisal of infant temperament during this same time period. Both hypotheses were supported in the study, indicating that the more traumatic the birth, the lower maternal self-efficacy 
and more negative appraisal of infant temperament. This is significant not only from a research standpoint, but clinically as well. 


\section{References}

Andersen, L., Melvaer, L., Videbech,P., Lamont, R., \& Joergensen, J. (2012). Risk factors for developing posttraumatic stress disorder following childbirth: A systematic review. Acta Obstetricia et Gynecologica Scandinavica, 91, 12611272.

Ainsworth, M. D., \& Bell, S. M. (1970). Attachment, exploration, and separation: Illustrated by the behavior of one-year-olds in a strange situation. Child Development, 41, 49-67.

Ainsworth, M. D. S., Blehar, M. C., Waters, E., \& Wall, S. (1978). Patterns of attachment: A psychological study of the strange situation. Hillsdale, $\mathrm{NJ}$ : Erlbaum.

Alcorn K., O'Donovan A., Patrick J., Creedy D, \& Devilly G. (2010). A longitudinal study of the prevalence of posttraumatic stress disorder resulting from childbirth events. Psychological Medicine, 40(11), 1849-1859.

Alder, J., Stadlmayr, W., Tschudin, S., \& Bitzer, J. (2006). Posttraumatic stress symptoms after childbirth: What should we offer? Journal of Psychosomatic Obstetrics \& Gynecology, 27(2), 107-112.

Alehagen, S., Wijma, B., Lundberg, U., \& Wijma, K. (2005). Fear, pain and stress hormones during childbirth. Journal of Psychosomatic Obstetrics \& Gynecology, 26(3), 153-165.

American Psychiatric Association (1980). Diagnostic and statistical manual of mental disorders. 3rd edn. Washington DC: American Psychiatric Association. 
American Psychiatric Association (2000). Diagnostic and statistical manual of mental disorders. 4th edn. -text revision. Washington DC: American Psychiatric Association.

Ansara, D., Cohen, M., Gallop, R., Kung, R., \& Schei, B. (2005). Predictors of women's physical health problems after childbirth. Journal of Psychosomatic Obstetrics and Gynecology,26(2), 115-125.

Atkins, R. (2010). Self-efficacy and the promotion of health for depressed single mothers. Mental Health in Family Medicine, 7, 155-168.

Ayers, S., Eagle, A., \& Waring, H. (2006). The effects of childbirth-related posttraumatic stress disorder on women and their relationships: A qualitative study. Psychology, Health \& Medicine, 11(4), 389-398.

Ayers, S., Harris, R., Sawyer, A., Parfitt, Y., \& Ford, E. (2009). Posttraumatic stress disorder after childbirth: Analysis of symptom presentation and sampling. Journal of Affective Disorders, 119(1-3), 200-204.

Ayers, S., Joseph, S., McKenzie-McHarg, K., Slade, P., \& Wijma, K. (2008). Posttraumatic stress disorder following childbirth: Current issues and recommendations for future research. Journal of Psychosomatic Obstetrics \& Gynecology, 29(4): 240-250.

Ayers, S., Wright, D., \& Wells, N. (2007). Symptoms of posttraumatic stress disorder in couples after birth: Association with couple's relationship and parent-baby bond. Journal of Reproductive and Infant Psychology, 25(1), 40-50. 
Bailham, D., \& Joseph, S. (2003). Posttraumatic stress following childbirth: A review of the emerging literature and directions for research and practice. Psychology, Health \& Medicine, 8 (2), 159-168.

Bandura, A. (1977). Self-efficacy: Toward a unifying theory of behavioral change. Psychological Review, 84, 191-215.

Bandura, A. (1995). Self-efficacy in changing societies. Oxford: Cambridge University Press.

Bandura, A. (1997). Self-efficacy: The exercise of control. New York: W.H. Freeman.

Bandura, A., Pastorelli, C., Barbaranelli, C., \& Caprara, G. (1999). Self-efficacy pathways to childhood depression. Journal of Personality and Social Psychology, 76, 258-269.

Bates, J., \& McFayden, S. (2000).Temperament and parent-child relations as interacting factors in children's behavioral adjustment. In Moifese, V. \& Moltesf, D. (Eds.), Temperament and personality development across the life span (pp. 141-176). Hillsdale, NJ: Lawrence Erlbaum.

Baumeister, R.F., \& Vohs, K.D. (2007). Self-regulation, ego depletion, and motivation. Social and Personality Psychology, 1(1), 115-128.

Beck, C. (2004). Posttraumatic stress disorder due to childbirth. Nursing Research, 53, 216-224.

Beck, C., Gable, R., Sakala, C., \& Declercq, E. (2011). Posttraumatic stress disorder in new mothers: Results from a two-stage national survey. Birth, 38(3), 216-227.

Benight, C.C., \& Bandura, A. (2004). Social cognitive theory of posttraumatic recovery: The role of perceived self-efficacy. Behaviour Research and Therapy, 42, 1129- 
1148.

Bentley, S. (2005). Short history of PTSD: From Thermopylae to Hue soldiers have always had a disturbing reaction to war. Vietnam Veterans of America: The Veteran. Retrieved June 7, 2012 from http://www.vva.org/archive/TheVeteran/2005 03/feature HistoryPTSD.htm

Biostat (2012). What is power? Power analysis. Power and Precision, Retrieved April 25, 2013 from http://www.power-analysis.com/effect size.htm.

Block, J. (2007). Pushed: The painful truth about childbirth and modern maternity care. Cambridge, Massachusetts: Da Capo Press.

Bowlby, J. (1982). Attachment and loss. Vol. 1: Attachment (2nd Ed.). New York: Basic Books.

Bowlby, J. (1973a). Attachment and loss. Vol 2: Separation: Anxiety and anger. New York: Basic Books.

Bowlby, J. (1973b). Attachment and loss. Vol 3: Loss: Sadness and depression. New York: Basic Books.

Brace, N., Snelgar, R., \& Kemp R. (2012). SPSS for psychologists. London: Palgrave MacMillan

Bridges, L.J., Palmer, S.A., Hurtado, M., \& Tsai, D. (1993). Agreement between affectively based observational and parent-report measures of temperament at infant age 6 months. Infant Behavior \& Development, 16, 501-506.

Bryanton, J., Gagnon, A., Harem, M., \& Johnston, C. (2008). Predictors of early parenting self-efficacy. Nursing Research, 57(4), 252-259. 
Buckley, S. (2010). Ecstatic birth: Nature's hormonal blueprint for labor. Mothering, $111,243-252$.

Carter, A., Garrity-Rokous, J., Chazan-Cohen, R., Little C., \& Briggs-Gowan, M. (2001). Maternal depression and comorbidity: Predicting early parenting, attachment security, and toddler social-emotional problems and competencies. Journal of the American Acadmey of Child and Adolescent Psychiatry, 40, 18-26.

Carter, C., Ahnert, L., Grossmann, K., Hrdy, S., Lamb, M., Porges, S., \& Sachser, N. (2005). Attachment and Bonding: A New Synthesis. Cambridge, MA: The MIT Press.

Chrousos G. \& Gold, P. (1992). The concepts of stress and stress system disorders. Overview of physical and behavioral homeostasis. JAMA, 267,1244-1252.

Cohen, J. (1992). A power primer. Psychological Bulletin, 112(1), 155-159.

Cohen, M., Ansara, D., Schei, B., Stuckless, N. \& Stewart, D. (2004). Posttraumatic stress disorder after pregnancy, labor, and delivery. Journal of Women's Health, 13, 315-324.

Coleman, P., \& Karraker, K. (1997). Self-efficacy and parenting quality: findings and future applications. Developmental Review, 18, 47-85.

Coleman, P., \& Karraker, K. (2000). Parenting self-efficacy among mothers of schoolage children: Conceptualization, measurement and correlates, Family Relations, $49,13-24$.

Coleman, P., \& Karraker, K. (2003). Maternal self-efficacy beliefs, competence in parenting, and toddlers' behavior and developmental status. Infant Mental Health Journal, 24(2), 126-148. 
Cooke S \& Bliss, V (2006). Plasticity in the human central nervous system, Brain, 129, 1659-73.

Cooklin, A.R., Giallo, R., \& Rose, N. (2011). Parental fatigue and parenting practices during early childhood: An Australian community survey. Child: Care, Health, and Development, 10, 1365-1377.

Crane, P. A., \& Clements, P. T. (2005). Psychological responses to disaster: Focus on adolescents. Journal of Psychosocial Nursing, 43(8), 31-38.

Creedy, D., Shochet, I., \& Horsfall, J. (2000). Childbirth and the development of acute trauma symptoms: Incidence and contributing factors. Birth Issues in Perinatal Care, 27, 104-111.

Czarnocka, J., \& Slade, P. (2000). Prevalence and predictors of posttraumatic stress symptoms following childbirth. British Journal of Clinical Psychology, 39, 35-51.

Davis, S., Bozon, B. \& Laroche, S. (2003) How necessary is the activation of the immediate early gene zif268 in synaptic plasticity and learning? Behavioral Brain Res., 142, 17-30.

Dickerson, S., Kemeny, M., Aziz, N., Kim, K., \& Fahey, J. (2004). Immunological effects of induced shame and guilt. Psychosomatic Medicine,66, 124-131.

Dieter J., Field T., Hernandez-Reif M (2001). Maternal depression and increased fetal activity. Obstetrics and Gynecology,21:468-73.

Donovan, W. L., Leavitt, L. A., \& Walsh, R. O. (1990). Maternal self-efficacy: Illusory control and its effect on susceptibility to learned helplessness. Child Development, 61, 1638-1647. 
Douglas, A. J., G. Leng, et al. (2002). The importance of oxytocin mechanisms in the control of mouse parturition. Reproduction 123(4): 543-52.

Drake, E., Humenick, S., Amankwaa, L., Younger, J., \& Roux, G. (2007). Predictors of maternal responsiveness. Journal of Nursing Scholarship, 39(2), 119-125.

Dumka, L.E., Stoerzinger, H.D., Jackson, K.M., \& Roosa, M.W. (1996). Examination of the cross-cultural and cross-language equivalence of the parenting self-agency measure. Family Relations, 45, 216-222.

Dunning, M. \& Giallo, R. (2012). Fatigue, parenting stress, self-efficacy and satisfaction in mothers of infants and young children. Journal of Reproductive and Infant Psychology, 2, 145-159.

Elek S.M., Hudson D.B. \& Bouffard C. (2003) Marital and parenting satisfaction and infant care self-efficacy during the transition to parenthood: the effect of infant sex. Issues in Comprehensive Pediatric Nursing 26, 45-57.

Elwood, L.S., Kathryn, S. H., Olatunji, B. O., \& Williams, N. L. (2009). Cognitive vulnerabilities to the development of PTSD: A review of four vulnerabilities and the proposal of an integrative vulnerability model. Clinical Psychological Review, 29, 87-100.

Everly, G.S. \& Lating, J.M. (2004). Personality-Guided Therapy for Posttraumatic Stress Disorder. Washington, DC: American Psychological Association. Eysenck, H.J. (1967). The biological basis of personality. Springfield, IL: Thomas. Field, A. (2005). Discovering statistics using SPSS: Second ed. London: Sage Publications. 
Flatten, D., Walte, G., \& Perlitz, V. (2008). Self-efficacy in acutely traumatized patients and the risk of developing a posttraumatic stress syndrome. GMS Psycho-SocialMedicine, 5, 1-8.

Foa, E., Keane, T., \& Friedman, M. (2000) Effective Treatments for PTSD. New York, NY: The Guilford Press.

Foa, E., Rothbaum, B., Riggs, D., \& Murdock, T. (1994).Treatment of posttraumatic stress disorder in rape victims: A comparison between cognitive behavioral procedures and counseling. Journal of Clinical Psychology, 59, 715-23.

Folkman, S., \& Moskowitz, J. T. (2000). Positive affect and the other side of coping. American Psychologist, 55, 647-654.

Freud, S. (1961). Introductory lectures on psychoanalysis. In J. Strachey (Ed. \& Trans.) The standard edition of the complete psychological works of Sigmund Freud, Nol. 17, pp.243-496).

Freud, S. \& Breuer, J. (1961). Studies on hysteria, in The Standard Edition of the Complete Psychological Works of Sigmund Freud, 2, pp. 1-321. London: Hogarth Press (originally published 1893-1895).

Friedman, Matthew J. Keane, Terence M. Resick, Patricia A. (2007). Handbook of PTSD: Science and Practice. New York, NY: Guilford Press.

Frommberger, U., Stieglitz, R., Straub, S., Nyberg, E, Schlickewei, W., Kuner, E., \& Berger, M. (1999). The concept of "sense of coherence" and the development of postraumatic stress disorder in traffic accident victims. Journal of Psychosomatic Research, 46(4):343-8. 
Gamble, J., Creedy, D., Moyle, W., Webster, J., McAllister, M. \& Dickson, P. (2005). Effectiveness of a Counseling Intervention after a Traumatic Childbirth: A Randomized Controlled Trial. Birth, 32, 11-19.

Gartstein, M., Putnam, S., Becken-Jones, L., \& Rothbart, M. (2002). Infant behavior questionnaire-revised: New evidence in support of reliability and validity. Presentation at the biannual convention of the International Society for Infant Study, Toronto, Canada, April 2002.

Giallo, R., Rose, N., \& Vittorino, R. (2011). Fatigue, well-being and parenting in mothers of infants and toddlers with sleep problems. Journal of Reproductive and Infant Psychology, 29(3), 236-249.

Gray, P., Edwards, D., O'Callaghan, M., Cuskelly, M., \& Gibbons, K. (2013). Parenting stress in mothers of preterm infants: Influence of development, temperament, and maternal depression. Early Human Development, 89(9), 625-629.

Hart, S., Stanley, C., Murray, L., \& Stein, A. (2004). The effect of postnatal depression on mother-infant interaction, infant response to the Still-face perturbation, and task performance on an instrumental learning task. Development and Psychopathology, 16, 1-18.

Heinrichs, M., Wagner, D., Schoch, W., Soravia, L., Hellhammer, D., \& Ehlert, U. Predicting posttraumatic stress symptoms from pretraumatic risk factors: A 2year prospective follow-up study in firefighters. American Journal of Psychiatry, 162(12), 2276-86.

Hess, E. (1973). Imprinting: Early experience and the development of psychobiology of attachment. New York: Hallmark Press. 
Hodnett, E.D. (2000). Caregiver support for women during childbirth. The Cochrane Database of Systematic Reviews, 4, 1-22.

Hofberg, K., \& Brockington, I. (2000). Tokophobia: an unreasoning dread of childbirth. British Journal of Psychiatry, 176, 83-85.

Holmes, J. (2001). The search for the secure base: Attachment theory and psychotherapy. New York: Brunner-Routledge.

Holmes, A.\&Wellman, C.L. (2009) Stress-induced prefrontal reorganization and executive dysfunction in rodents. Neuroscience and Biobehavioral Review, 33, 773-783.

Horowitz, M.J. (1986). Stress response syndromes: A review of posttraumatic and adjustment disorders. Hospital and Community Psychiatry, 37(3), 241-249.

Huizink, A., Robles de Medina, P., Mulder, E., Visser, G., Buitelaar, J. (2002).

Psychological measures of prenatal stress as predictors of infant temperament. Journal of the American Academy of Child \& Adolescent Psychiatry 41 10781085.

Jackson, A. P. (2000). Maternal self-efficacy and children's influence on stress and parenting among single Black mothers in poverty. Journal of Family Issues, 21, $3-16$.

Janet, P. (1919). Les medications psychologiques (Vol. 3), Félix Alcan, Paris. (Reprint: Société Pierre Janet, Paris, 1984). English edition: Principles of Psychotherapy (Vol. 2), Macmillan, New York. (Reprint: Arno Press, New York, 1976). 
Johnson, K.C., \& Daviss, B. (2005). Outcomes of planned home births with certified professional midwives: Large prospective study in North America. British Medical Journal, 330, 1416-1419.

Johnston, C., \& Mash, E. (1989). A measure of parenting satisfaction and efficacy. Journal of Clinical Child Psychology, 18(2), 167-175.

Jones, F., \& Bright, J. (2001). Stress: Myth, Theory and Research. Harlow, England: Pearson Education Limited.

Jones, T., \& Prinz, R. (2005). Potential roles of parental self-efficacy in parent and child adjustment: A review. Clinical Psychology Review, 2, 342-363.

Joseph, S. (1999). Social support and mental health following trauma. Chapter in Posttraumatic stress disorders: Concepts therapy. Chichester: Wiley. Jung, C.G. (1971). Psychological types: The collected work of CG Jung, Volume 6, London: Routledge. (Originally published in 1921).

Kaiser (2011). Kaiser family foundation, US Global Health Policy. Retrieved on September 6, 2011 from http://www.globalhealthfacts.org.

Kanninen, K., Puinamkai, R., \& Qouta, S. (2002). The relation of appraisal, coping efforts, and acuteness of trauma to PTS symptoms among former political prisoners. Journal of Traumatic Stress, 15, 245-253.

Kardiner, A. (1941). The traumatic neuroses of war. New York: Paul B. Hoeber. Kardiner, A. \& Spiegel, H. (1947). War stress and neurotic illness. New York: Paul B. Hoeber.

Keogh, E., Ayers, S., \& Francis, H. (2002). Does anxiety sensitivity predict posttraumatic stress symptoms following childbirth? A preliminary report. Cognitive 
Behaviour Therapy, 31(4), 145-155.

Kessler, R. C., Berglund, P., Demler, O., Jin, R., Merikangas, K. R., \& Walters, E. (2005). Lifetime prevalence and age-of-onset distributions of DSM-IV disorders in the National Comorbidity Survey Replication. Archives of General Psychiatry, 62, 593-602.

Kingston, D., Tough, S., \& Whitfield, H. (2012). Prenatal and Postpartum Maternal Psychological Distress and Infant Development: A Systematic Review. Child Psychiatry and Human Development (43) 683-714.

Kirsch, P., C. Esslinger, et al. (2005). Oxytocin modulates neural circuitry for social cognition and fear in humans. Journal of Neuroscience 25(49): 11489-93.

Krystal, H. (1968). Massive psychic trauma. New York: International Universities Press.

Krystal, H. (1988). Integration and self-healing. Hillsdale, NJ: Analytic Press.

Lapp, L., Agbokou, C., Perreti, C., \& Ferreri, F. (2010). Management of posttraumatic stress disorder after childbirth: A review. Journal of Psychosomatic Obstetrics \& Gynecology, 31(3), 113-122.

Lazarus, R., \& Folkman, S. (1984). Stress, Appraisal and Coping. New York: Springer.

Leake, R. D., R. E. Weitzman, et al. (1981). Oxytocin concentrations during the neonatal period. Biology of the Neonate 39(3-4): 127-31.

Lochner, H., Bhandari, M., \& Tornetta, P. (2001). Type II error rates of randomized trials in orthopedic trauma. Journal of Bone and Joint Surgery, 83, 1650-1655. 
Lovejoy, M.C., Verda, M.R., \& Hays, C.E. (1997). Convergent and discriminant validity of measures of parenting efficacy and control. Journal of Clinical Child Psychology, 26, 366-376.

Lombardo, T. \& Gray, M. (2005). Beyond Exposure for Posttraumatic Stress Disorder (PTSD) Symptoms: Broad-Spectrum PTSD Treatment Strategies. Behavior Modification, 29, 3-9.

Lyons, S. (1998). A prospective study of posttraumatic stress symptoms 1 month following childbirth. Journal of Reproductive and Infant Psychology, 16, 91-105.

Maggioni, C., Margola, D., \& Filippi, F. (2006). PTSD, risk factors, and expectations among women having a baby: A two-wave longitudinal study. Journal of Psychosomatic Obstetrics and Gynecology, 27 (2), 81-90.

Mantymaa, M., Puura, K., Luoma, I., Salmelin, R., \& Tamminen, T. (2006). Mother's early perception of her infant's difficult temperament, parenting stress and early mother-infant interaction. Nord J Psychiatry, 60, 379-386.

Maren, S. (2001) Neurobiology of Pavlovian fear conditioning. Annual Review of Neuroscience, 24, 897-931.

Maren, S. \& Quirk, G.J. (2004) Neuronal signalling of fear memory. Annual Review of Neuroscience, 5, 844-852.

Marlowe, D. H. (2000). Psychological and psychosocial consequences of combat and deployment with special emphasis on the Gulf War. Retrieved on June 7, 2012 from http://www.gulflink.osd.mil/library/randrep/marlowe_paper/ 
Meades, R., Pond, C., Ayers, S., \& Warren, F. (2011). Postnatal debriefing: Have we thrown the baby out with the bath water. Behaviour Research and Therapy, 49(5), 367-372.

Mebert, C.J. (1991). Dimensions of subjectivity in parents' ratings of infant temperament Child Development, 62, 352-361.

Milne L., Greenway P., Guedeney, A.(2009). Long-term developmental impact of social withdrawal in infants. Infant Behavior and Development, 32:159-66.

Moberg, K.U. (2003). The oxytocin factor. Cambridge, Massachusetts: Da Capo Press. Myers, C.S. (1915) A contribution to the study of shell shock. Lancet, 1, pp.316-320.

Nicholls, K., \& Ayers, S. (2007). Childbirth-related posttraumatic stress disorder in couples: A qualitative study. British Journal of Health Psychology, 12, 491-509.

Obegi, J., \& Berant, E. (2009). Attachment Theory and Research in Clinical Work with Adults. New York, NY: The Guilford Press.

Odent, M. (2001). The Scientification of Love. London: Free Association Books.

Ohan, J.L., Leung, D.W., \& Johnston, C. (2000). The parenting sense of competence scale: evidence of a stable factor structure and validity. Canadian Journal of Behavioral Science, 32, 251-261.

Olde E, van der Hart O, Kleber R, van Son M, Wijnen H., Pop, V. (2006). Peritraumatic dissociation and emotions as predictors of PTSD symptoms following childbirth. Journal of Trauma Dissociation, 6:125-142.

Olff, M., Langeland, W., Draijer, N., \& Gersons, B.. (2007). Gender differences in posttraumatic stress disorder. Psychological Bulletin, 133, 183-204. 
Parfitt, Y., \& Ayers, S. (2009). The effect of post-natal symptoms of posttraumatic stress and depression on the couple's relationship and parent-baby bond. Journal of Reproductive and Infant Psychology, 27(2), 127-142.

Pavlov, I.P. (1927). Conditioned reflexes. London: Oxford University Press.Porter, C. \& Hsu, H. (2003). First-time mothers' perceptions of efficacy during the transition to motherhood: Links to infant temperament. Journal of Family Psychology, 17, 54-64.

Pedhazur, E. (1997). Multiple regression in behavior research. Fort Worth, TX: HarcourtBrace.

Pennell, C., Whittingham, K., Boyd, R., Sanders, M., \& Colditz, P. (2012). Prematurity and parental self-efficacy: The preterm parenting \& self-efficacy checklist. Infant Behavior \& Development, 35(4),p678-688.

Perez-Blasco, J., Viguer, P., \& Rodrigo, M. (2013). Effects of a mindfulness-based intervention on psychological distress, well-being, and maternal self-efficacy in breastfeeding mothers: The results of a pilot study. Archives of Women's Mental Health, 16(3), 227-236.

Reznick, J.S., Gibbons, J.L., Johnson, M.O., \& McDonough, P.M. (1989). Behavioral inhibition in a normative sample. In J.S. Reznick (Ed.), Perspectives on behavioral inhibition (pp. 25-49). Chicago: University of Chicago Press.

Roozendaal, B., McEwen, B.S. \& Chattarji, S. (2009) Stress, memory and the amygdala. National Review of Neuroscience, 10, 423-433.

Rothbart, M.K. (1981). Measurement of temperament in infancy. Child Development, $52,569-578$. 
Rothschild, B. (2000). The body remembers: The psychophysiology of trauma and trauma treatment. New York: W.W. Norton \& Co.

Rubin, D. C., Bernstein, D., \& Bohni, M. K. (2008). A memory-based model of posttraumatic stress disorder: Evaluating basic assumptions underlying the PTSD diagnosis. Psychological Review, 115, 985-1001.

Rutter, Michael (1995). Clinical Implications of Attachment Concepts: Retrospect and Prospect. Journal of Child Psychology \& Psychiatry 36 (4): 549-71.

Ruzek, J. I., Brymer, M. J., Jacobs, A. K., Layne, C. M., Vernberg, E. M., \& Watson, P. J. (2007). Psychological first aid. Journal of Mental Health Counseling, 29(1), 1749.

Saigh, P.A. and Bremner, J.D. (1999). Posttraumatic Stress Disorder: A Comprehensive Text. Boston: Allyn and Bacon.

Salonen, A., Kaunonen, M., Astedt-Kurki, P., Jarvenpaa, H., \& Tarkka, M-T. (2009). Parenting self-efficacy after childbirth. Journal of Advanced Nursing, 65(81), 2324-2336.

Sapolsky, R., Romero, L., \& Munck, A. (2000). How do glucocorticoids influence stress response? Integrating permissive, suppressive, stimulatory, and preparative actions. Endocrine Review, 21(1), 55-89.

Segal, S., \& Csavoy(1998). The tocolytic effect of catecholamines in the gravid rat uterus. Anesthesia 87(4): 864-9.

Selyë, H. (1936). A syndrome produced by diverse nocuous agents. The Journal of Neuropsychiatry and Clinical Neurosciences, 138:32.

Selyë, H. (1976). The Stress of Life (revised edition), New York: McGraw-Hill. 
Selyë, H. (1993). History of the stress concept. In L. Goldberger and S. Breznitz (Eds) Handbook of Stress: theoretical and Clinical Aspects (2nd edition). New York: the Free Press.Sevigny, P. \& Loutzenhiser, L. (2010). Predictors of parenting self-efficacy in mothers and fathers of toddlers. Child: Care, Health, and Development, 36(2), 179-189.

Sevigny, P. \& Loutzenhizer, L. (2009). Predictors of parenting self-efficacy in mothers and fathers of toddlers. Child: Care, Health and Development, 36(2), 179-189. Sheldon, W.H. (1940). Varieties of human physique. London: Hafler Publishing Company.

Skinner, B. F. (1938). The Behavior of Organisms: An Experimental Analysis. Cambridge, Massachusetts: B.F. Skinner Foundation.

Skinner, B. F. (1971). Beyond Freedom and Dignity. New York: Bantam Vintage.

Soderquist, J., Wijma, B., \& Wijma, K. (2006). The longitudinal course of posttraumatic stress after childbirth. Journal of Psychosomatic Obstetrics \& Gynecology, 27(2): 113-119.

Soet, J., Brack, G., \& Dilorio, C. (2003). Prevalance and predictors of women's experience of psychological trauma during childbirth, Birth, 30(1): 36-46.

Spielman, V., \& Taubman-Ben Ari, O.(2009). Parental self-efficacy and stress-related growth in the transition to parenthood: A comparison between parents of preand full-term babies. Health and Social Work, 34(3), 201-12.

Stamrood, C.A., Huisin'Tveld, E.M., Van Pampus, M.G., Berger, L.W., Vingerhoets, J.J., Willibrord, C.M., Schultz, W., Van den Berg, P.P., Van Sonderen, E.L., \& Paarlberg, K.M. (2010). Measuring posttraumatic stress following childbirth: a 
critical evaluation of instruments. Journal of Psychosomatic Obstetrics \& Gynecology, 31(1): 40-49.

Stanford, S.C., \& Salmon P. (1993). Decoding the neurochemical basis of resistance to stress: a reply. Psychopharmacology 7, 89-90

Stapleton, J.A., Taylor, S., and Asmundson, G.J.G. (2006). Effects of Three PTSD Treatments on Anger and Guilt: Exposure therapy, Eye Movement Desensitization Reprocessing, and relaxation training. Journal of Traumatic Stress, 19, 19-28.

Statsoft. (2011). Power analysis. Retrieved May 31, 2012, from http://www.statsoft.com/textbook/power-analysis/

Streiner, D.L. (1990). Sample size and power and psychiatric research. Can J Psychiatry, 35, 616-20.

Stuber, J., Resnick, H., \& Galea, S. (2006). Gender disparities in posttraumatic stress disorder after mass trauma. Gender Medicine, 3(1), 54-67.

Tabachnick, B.G. \& Fidell, L.S. (2013). Using multivariate statistics ( $6^{\text {th }}$ ed.) Boston: Allyn and Bacon.

Terry, D. J. (1994). Determinants of coping: The role of stable and situational factors. Journal of Personality and Social Psychology, 66, 895-910.

Teti, D., \& Gelfand, D. (1991). Behavioral competence among mothers of infants in the first year: The mediational role of maternal self-efficacy. Child Development, 62, 918-929.

Thomas, S. \& Palmiter, R. (1997). Impaired maternal behavior in mice lacking norepinephrine and epinephrine Cell 91(5): 583-92. 
Tolin, D. F., \& Foa, E. B. (2006). Sex differences in trauma and posttraumatic stress disorder: A quantitative review of 25 years of research. Psychological Bulletin, 132, 959-992.

Tronick, E., \& Field, T. (1986). Maternal depression and infant disturbance. San Francisco, CA: Jossey Bass

van der Kolk, B. A., van der Hart, O., \& Marmar, G. (1996). Dissociation and information processing in posttraumatic stress disorder. In B. A. van der Kolk, A. C. McFarlane, \& L. Weisaeth (Eds.), Traumatic stress: The effects of overwhelming experience in mind, body and society (pp. 303-j327). New York: Guilford.

Verreault, N., DaCosta, D., Marchand, A., Ireland, K., Banack, H., Dritsa, M., \& Khalife, S. (2012) PTSD following childbirth: A prospective study of incidence and risk factors in Canadian women. Journal of Psychosomatic Research, 212-224.

Voeghtline, K., \& Stifter, C. (2010). Late preterm birth, maternal symptomatology, and infant negativity. Infant Behavior \& Development, 33(4), 545-554.

Vogt, D. (2007). National Center for PTSD, Professional Section. Retrieved on October 31, 2012 from http://www.ptsd.va.gov/professional/pages/women-traumaptsd.asp

Vyas, A., Mitra, R., Shankaranarayana Rao, B.S. \& Chattarji, S. (2002) Chronic stress induces contrasting patterns of dendritic remodeling in hippocampal and amygdaloid neurons. Journal of Neurosciences, 22, 6810-6818..

Vythilingum, B. (2010). Should childbirth be considered a stressor sufficient to meet the criteria for PTSD? Archives of Women's Mental Health, 13, 49-50. 
Whittaker, K. and Cowley, S. (2012). A survey of parental self-efficacy experiences: maximising potential through health visiting and universal parenting support. Journal of Clinical Nursing, 21, 3276-3286.

Wijma, K., Soderquist, J., and Wijma, B. (1997). Posttraumatic stress disorder after childbirth: A cross sectional study. Journal of Anxiety Disorders, 11, 587-597.

Wright, D. (1997). Understanding statistics: An introduction for the social sciences. London: Sage.

Yehuda, R. (2002a). Posttraumatic stress disorder. The New England Journal of Medicine, 346, 108-114.

Yehuda, R. (2002b). Neuroendocrine alterations in posttraumatic stress disorder. Primary Psychiatry, 9(2), 30-34.

Yehuda, R., Southwick, S., Nussbaum, G., Wahby, V., Giller, E., \& Mason, J. (1990). Low urinary cortisol excretion in patients with posttraumatic stress disorder. Journal of Nervous and Mental Disease, 178, 366-369.

Zeiss, A., Gallagher-Thompson, D., Lovett, S., Rose, J., \& McKibbin, C. (1999). Selfefficacy as a mediator of caregiver coping: Development and testing of an assessment model. Journal of Clinical Geropsychology, 5, 221-230. 
Appendix A: Demographic Information

Please answer the following questions regarding your most recent birth.

1. Your age:

2. Race (choose one):

Caucasian African American Asian Hispanic Pacific Islander Other

3. Partner status

Single Partnered

4. Highest level of education completed (Choose one):

Less than high school diploma High school diploma / GED

Some college Associate's degree Bachelor's degree

Master's degree Doctorate or above

5. \# of prior births (Not counting this one):

6. Gestational age in weeks at time of delivery:

7. Place of birth: (Choose one):

Home Hospital Birthing Center Other

8. Mode of delivery (Choose one):

Vaginal Planned C/ Section Unplanned C/Section VBAC

9. Primary mode of infant feeding (Choose one):

Breast Bottle Combination 


\section{Appendix B: Traumatic Event Scale-Form B (TES-B)}

Traumatic Event Scalle (TES)

(C) 1999 K. Wijma

\section{Delivery date:}

Today's date:

\section{INSTRUCTION}

Below you will find a number of statements that women have used to describe how they felt after childbirth. Read every statement once and circle the answer (1-4) that best corresponds at present with your experience. There are no right or wrong answers!

\section{How would you describe your delivery?}

a. The labor/delivery was a trying experience

b. During labor/delivery I felt physically offended

c. During labor/delivery I was afraid that I or my baby would be hurt or was going to die

d. During labor/delivery I felt anguished, helpless or horrified $\begin{array}{llll}\text { not } & \text { some- } & \text { much } & \text { very } \\ \text { at all } & \text { what } & & \text { much }\end{array}$

Number:

$\begin{array}{llll}1 & 2 & 3 & 4 \\ 1 & 2 & 3 & 4 \\ 1 & 2 & 3 & 4 \\ 1 & 2 & 3 & 4\end{array}$

\section{How are you doing now?}

Please continue with the statements below and describe how you feel at present. Answer by marking 1 (not at all) to 4 (often).

$\begin{array}{lll}\text { not } & \text { rarely } & \begin{array}{l}\text { some- often } \\ \text { times }\end{array}\end{array}$

1. Unpleasant thoughts and images of the childbirth $\quad \begin{array}{llll}1 & 2 & 3 & 4\end{array}$ experience force themselves on me

2. I have unpleasant dreams about the childbirth experience $\begin{array}{lllll}1 & 2 & 3 & 4\end{array}$

3. Suddenly I feel like the childbirth is recurring and I am filled with horrifying feelings

$\begin{array}{llll}1 & 2 & 3 & 4\end{array}$

4. All reminders of my childbirth experience cause intense $\quad \begin{array}{lllll}1 & 2 & 3 & 4\end{array}$ psychological distress

5. Reminders of the childbirth experience cause physical distress (i.e. heart beats faster, increased breathing, feeling tense, starting to sweat)

$\begin{array}{llll}1 & 2 & 3 & 4\end{array}$


6. I try to stay away from thoughts, emotions or conversations that might remind me of the childbirth experience

7. I try to avoid activities, places or persons that might remind me of the childbirth experience

8. I have difficulties remembering important parts of the labor/delivery

9. I have difficulties being engaged in activities I enjoyed before giving birth

10. I feel detached or estranged from other people

11. My ability to love or be affectionate is restricted

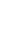

$\begin{array}{lll}2 & 3 & 4\end{array}$

12. I feel that my future is meaningless

13. I have difficulties falling or staying asleep because thoughts and memories of the labor/delivery disturb me

14. I can suddenly feel very irritated or angry for no reason

15. I find it difficult to concentrate

$\begin{array}{llll}1 & 2 & 3 & 4 \\ 1 & 2 & 3 & 4 \\ 1 & 2 & 3 & 4 \\ 1 & 2 & 3 & 4\end{array}$

17. I react strongly to unexpected events

$\begin{array}{llll}1 & 2 & 3 & 4 \\ 1 & 2 & 3 & 4 \\ 1 & 2 & 3 & 4 \\ 1 & 2 & 3 & 4\end{array}$

16. I always feel tense and alert

4 


\title{
Appendix C: Parenting Sense of Competence Scale
}

\author{
Being A Parent - Mother
}

Name:

Date:

Listed below are a number of statements. Please respond to each item, indicating your agreement or disagreement with each statement in the following manner.

If you strongly agree, circle the letters SA

If you agree, circle the letter A

If you mildly agree, circle the letters MA

If you mildly disagree, circle the letter MD

If you disagree, circle the letter D

If you strongly disagree, circle the letter SD

1. The problems of taking care of a child are easy

SA A MA MD D SD

to solve once you know how your actions affect

your child, an understanding I have acquired.

2. Even though being a parent could be rewarding,

SA A MA MD D SD

I am frustrated now while my child is at his/her

Present age.

3. I go to bed the same way I wake up in the

SA A MA MD D SD

morning - feeling I have not accomplished a

whole lot.

4. I do not know what it is, but sometimes when

SA A MA MD D SD

I'm supposed to be in control, I feel more like

the one being manipulated.

5. My mother was better prepared to be a good

SA A MA MD D SD

mother than I am.

6. I would make a fine model for a new mother

SA A MA MD D SD to follow in order to learn what she would need to know in order to be a good parent.

7. Being a parent is manageable, and any problems are easily solved.

8. A difficult problem in being a parent is not knowing whether you're doing a good job

SA A MA MD D SD or a bad one.

SA A MA MD D SD 
9. Sometimes I feel like I'm not getting anything done.

10. I meet my own personal expectations for expertise in caring for my child.

11. If anyone can find the answer to what is troubling my child, I am the one.

12. My talents and interests are in other areas, not in being a parent.

13. Considering how long I've been a mother, I feel thoroughly familiar with this role.

14. If being a mother of a child were only more interesting, I would be motivated to do a better job as a parent.

15. I honestly believe I have all the skills necessary to be a good mother to my child.

16. Being a parent makes me tense and anxious.
SA A MA MD D SD

SA A MA MD D SD

SA A MA MD D SD

SA A MA MD D SD

SA A MA MD D SD

SA A MA MD D SD

SA A MA MD D SD

SA A MA MD D SD

Appendix D: Infant Behavior Questionnaire-Revised (IBQ-R) 


\section{Very Short Form}

Subject No.

Today's Date

Sex of Child
Date of Baby's Birth

Age of Child $\overline{\text { month. }} \overline{\text { day }} \overline{\text { year }}$

$\overline{\text { mos. }} \overline{\text { weeks }}$

\section{INSTRUCTIONS:}

Please read carefully before starting:

As you read each description of the baby's behavior below, please indicate how often the baby did this during the LAST WEEK (the past seven days) by circling one of the numbers in the left column. These numbers indicate how often you observed the behavior described during the last week.

\begin{tabular}{|c|c|c|c|c|c|c|c|}
\hline 1 & 2 & 3 & 4 & 5 & 6 & 7 & NA \\
\hline Never & $\begin{array}{c}\text { Very } \\
\text { Rarely }\end{array}$ & $\begin{array}{c}\text { Less } \\
\text { Than } \\
\text { Half the } \\
\text { Time }\end{array}$ & $\begin{array}{c}\text { About } \\
\text { Half the } \\
\text { Time }\end{array}$ & $\begin{array}{c}\text { More } \\
\text { Than } \\
\text { Half the } \\
\text { Time }\end{array}$ & $\begin{array}{c}\text { Almost } \\
\text { Always }\end{array}$ & Always & $\begin{array}{c}\text { Does Not } \\
\text { Apply }\end{array}$ \\
\hline
\end{tabular}

The "Does Not Apply" (X) column is used when you did not see the baby in the situation described during the last week. For example, if the situation mentions the baby having to wait for food or liquids and there was no time during the last week when the baby had to wait, circle the (X) column. "Does Not Apply" is different from "Never" (1). "Never" is used when you saw the baby in the situation but the baby never engaged in the behavior listed during the last week. For example, if the baby did have to wait for food or liquids at least once but never cried loudly while waiting, circle the (1) column.

Please be sure to circle a number for every item.

1. When being dressed or undressed during the last week, how often did the baby squirm and/or try to roll away?

$$
\begin{array}{llllllll}
1 & 2 & 3 & 4 & 5 & 6 & 7 & \text { NA }
\end{array}
$$

2. When tossed around playfully how often did the baby laugh?

$\begin{array}{llllllll}1 & 2 & 3 & 4 & 5 & 6 & 7 & \text { NA }\end{array}$

3. When tired, how often did your baby show distress?

$\begin{array}{llllllll}1 & 2 & 3 & 4 & 5 & 6 & 7 & \text { NA }\end{array}$

4. When introduced to an unfamiliar adult, how often did the baby cling to a parent? 


$$
\begin{array}{llllllll}
1 & 2 & 3 & 4 & 5 & 6 & 7 & \text { NA }
\end{array}
$$

5. How often during the last week did the baby enjoy being read to?

$$
\begin{array}{llllllll}
1 & 2 & 3 & 4 & 5 & 6 & 7 & \mathrm{NA}
\end{array}
$$

6. How often during the last week did the baby play with one toy or object for 5-10 minutes?

$$
\begin{array}{llllllll}
1 & 2 & 3 & 4 & 5 & 6 & 7 & \text { NA }
\end{array}
$$

7. How often during the week did your baby move quickly toward new objects?

$$
\begin{array}{llllllll}
1 & 2 & 3 & 4 & 5 & 6 & 7 & \text { NA }
\end{array}
$$

8. When put into the bath water, how often did the baby laugh?

$$
\begin{array}{llllllll}
1 & 2 & 3 & 4 & 5 & 6 & 7 & \text { NA }
\end{array}
$$

9. When it was time for bed or a nap and your baby did not want to go, how often did $\mathrm{s} /$ he whimper or sob?

$$
\begin{array}{llllllll}
1 & 2 & 3 & 4 & 5 & 6 & 7 & \text { NA }
\end{array}
$$

10. After sleeping, how often did the baby cry if someone doesn't come within a few minutes?

$$
\begin{array}{llllllll}
1 & 2 & 3 & 4 & 5 & 6 & 7 & \mathrm{NA}
\end{array}
$$

11. In the last week, while being fed in your lap, how often did the baby seem eager to get away as soon as the feeding was over?

$$
\begin{array}{llllllll}
1 & 2 & 3 & 4 & 5 & 6 & 7 & \text { NA }
\end{array}
$$

12. When singing or talking to your baby, how often did s/he soothe immediately?

$$
\begin{array}{llllllll}
1 & 2 & 3 & 4 & 5 & 6 & 7 & \text { NA }
\end{array}
$$

13. When placed on his/her back, how often did the baby squirm and/or turn body?

$\begin{array}{llllllll}1 & 2 & 3 & 4 & 5 & 6 & 7 & \text { NA }\end{array}$

14. During a peekaboo game, how often did the baby laugh?

$\begin{array}{llllllll}1 & 2 & 3 & 4 & 5 & 6 & 7 & \text { NA }\end{array}$


15. How often does the infant look up from playing when the telephone rings?

$\begin{array}{llllllll}1 & 2 & 3 & 4 & 5 & 6 & 7 & \text { NA }\end{array}$

16. How often did the baby seem angry (crying and fussing) when you left her/him in the crib?

$\begin{array}{llllllll}1 & 2 & 3 & 4 & 5 & 6 & 7 & \mathrm{NA}\end{array}$

17. How often during the last week did the baby startle at a sudden change in body position (e.g., when moved suddenly)?

$\begin{array}{llllllll}1 & 2 & 3 & 4 & 5 & 6 & 7 & \mathrm{NA}\end{array}$

18. How often during the last week did the baby enjoy hearing the sound of words, as in nursery rhymes?

$\begin{array}{llllllll}1 & 2 & 3 & 4 & 5 & 6 & 7 & \text { NA }\end{array}$

19. How often during the last week did the baby look at pictures in books and/or magazines for 5 minutes or longer at a time?

$\begin{array}{llllllll}1 & 2 & 3 & 4 & 5 & 6 & 7 & \text { NA }\end{array}$

20. When visiting a new place, how often did your baby get excited about exploring new surroundings?

$\begin{array}{llllllll}1 & 2 & 3 & 4 & 5 & 6 & 7 & \mathrm{NA}\end{array}$

21. How often during the last week did the baby smile or laugh when given a toy?

$\begin{array}{llllllll}1 & 2 & 3 & 4 & 5 & 6 & 7 & \text { NA }\end{array}$

22. At the end of an exciting day, how often did your baby become tearful?

$$
\begin{array}{llllllll}
1 & 2 & 3 & 4 & 5 & 6 & 7 & \mathrm{NA}
\end{array}
$$

23. How often during the last week did the baby protest being placed in a confining place (infant seat, play pen, car seat, etc.)?

$\begin{array}{llllllll}1 & 2 & 3 & 4 & 5 & 6 & 7 & \text { NA }\end{array}$


24. When being held, in the last week, did your baby seem to enjoy him/herself?

$\begin{array}{llllllll}1 & 2 & 3 & 4 & 5 & 6 & 7 & \text { NA }\end{array}$

25. When showing the baby something to look at, how often did s/he soothe immediately?

$\begin{array}{llllllll}1 & 2 & 3 & 4 & 5 & 6 & 7 & \mathrm{NA}\end{array}$

26. When hair was washed, how often did the baby vocalize?

$\begin{array}{llllllll}1 & 2 & 3 & 4 & 5 & 6 & 7 & \text { NA }\end{array}$

27. How often did your baby notice the sound of an airplane passing overhead?

$$
\begin{array}{llllllll}
1 & 2 & 3 & 4 & 5 & 6 & 7 & \mathrm{NA}
\end{array}
$$

28. When introduced to an unfamiliar adult, how often did the baby refuse to go to the unfamiliar person?

$$
\begin{array}{llllllll}
1 & 2 & 3 & 4 & 5 & 6 & 7 & \mathrm{NA}
\end{array}
$$

29. When you were busy with another activity, and your baby was not able to get your attention, how often did s/he cry?

$$
\begin{array}{llllllll}
1 & 2 & 3 & 4 & 5 & 6 & 7 & \text { NA }
\end{array}
$$

30. How often during the last week did the baby enjoy gentle rhythmic activities, such as rocking or swaying?

$$
\begin{array}{llllllll}
1 & 2 & 3 & 4 & 5 & 6 & 7 & \text { NA }
\end{array}
$$

31. How often during the last week did the baby stare at a mobile, crib bumper or picture for 5 minutes or longer?

$$
\begin{array}{llllllll}
1 & 2 & 3 & 4 & 5 & 6 & 7 & \text { NA }
\end{array}
$$

32. When the baby wanted something, how often did s/he become upset when $\mathrm{s} /$ he could not get what $\mathrm{s} /$ he wanted?

$\begin{array}{llllllll}1 & 2 & 3 & 4 & 5 & 6 & 7 & \text { NA }\end{array}$

33. When in the presence of several unfamiliar adults, how often did the baby cling to a parent?

$\begin{array}{llllllll}1 & 2 & 3 & 4 & 5 & 6 & 7 & \text { NA }\end{array}$


34. When rocked or hugged, in the last week, did your baby seem to enjoy him/herself?

$\begin{array}{llllllll}1 & 2 & 3 & 4 & 5 & 6 & 7 & \text { NA }\end{array}$

35. When patting or gently rubbing some part of the baby's body, how often did s/he soothe immediately?

$\begin{array}{llllllll}1 & 2 & 3 & 4 & 5 & 6 & 7 & \text { NA }\end{array}$

36. How often did your baby make talking sounds when riding in a car?

$\begin{array}{llllllll}1 & 2 & 3 & 4 & 5 & 6 & 7 & \text { NA }\end{array}$

37. When placed in an infant seat or car seat, how often did the baby squirm and turn body?

$\begin{array}{llllllll}1 & 2 & 3 & 4 & 5 & 6 & 7 & \text { NA }\end{array}$




\section{Appendix E: Recruitment Letter and URL}

\section{Dear List Participant:}

If you have an infant between the ages of 3 and 12 months, you are invited to participate in a study examining birth trauma and the impact it may have on how you feel about your baby's attitude / mood, and also how you feel about yourself in the mothering role. Your help is needed!

The study is being conducted by Teresa Stire, doctoral student in counseling psychology at West Virginia University. I would greatly appreciate your assistance in completing a series of online questionnaires that will take 15-20 minutes.

Please also consider assisting with recruiting participants by forwarding this invitation to all other mothers of infants ages 3-12 months.

If you have any questions or concerns, please contact me at tstire@mix.wvu.edu or my faculty advisor, Dr. James Bartee, at james.bartee@mail.wvu.edu.

Please follow the link below to find out more information and/or participate in the study: [insert link here]

Thank you, Teresa Stire, MA Counseling Psychology Doctoral Candidate West Virginia University tstire@mix.wvu.edu (304) 692-1131 
Appendix F: Consent to Participate

Title of the Study: Examining childbirth-related trauma and its effects on maternal selfefficacy and appraisal of infant temperament

Purpose: The purpose of this study is to survey women have given birth recently. We hope to understand how a difficult birth may affect a mother's feelings about her baby's attitude / mood, and also how it may affect how the woman feels about herself as a mother.

Procedures: Your participation will involve answering several surveys online. The four surveys will ask you to answer some background questions about yourself, questions about your most recent birth, how you see yourself as a mother, and to answer some questions about your baby. It is expected that your participation to complete these online surveys will take 15-20 minutes.

Risks and Benefits: There is minor risk to participating in this study. The answers you provide will be kept confidential (private) and your surveys will be anonymous, meaning that they will not be connected to your name, only a number code that is assigned to your surveys. If you feel emotional nervousness while completing the surveys, please look at the resources provided at the end of the survey.

There are slight benefits from participating in this study. Possible benefits may include a feeling of satisfaction that you helped with an understanding of how mothers feel about themselves and their babies, as well as how their birth experiences may affect these feelings.

Right to Withdraw: Your input in this study is entirely voluntary (you do not have to participate). You may choose not to participate in the study and you have the right to stop the survey at any time. If you choose to participate and later wish to withdraw from the study, there is no way to identify your document after it has been turned into the investigator because it will not have your name on it. If you are participating in an anonymous online survey like this one, once you submit your responses, the data cannot be linked to you and cannot be withdrawn.

For More Information: If you have any questions about this study, you may call Teresa Stire at tstire@mix.wvu.edu or (304)692-1131. If you still have questions, you may contact the principal investigator, James Bartee, Ph.D. at james.bartee@mail.wvu.edu or (304) 293-2227. You may also contact Lilo Ast at the West Virginia University Institutional Review Board office, at lilo.ast@mail.wvu.edu or (304) 293-7555. 
By completing the following survey you agree to participate in the project entitled, Examining childbirth-related trauma and its effects on maternal self-efficacy and appraisal of infant temperament 
Appendix G: IRB Approval

IRB protocol number: $\underline{1305042634}$

Title: Examining childbirth trauma and its effects on maternal self-efficacy and appraisal of infant temperament.

PI: James Bartee

The West Virginia University Institutional Review Board approved the above-referenced protocol on \{PROTOCOL_LAST_APPROVAL_DATE\}. To access this protocol, click on the protocol number link provided. Your approval letter can be found in the History subsection of the Summary \& History section located on the Protocol Actions page. For more information, see the Viewing Correspondence quick reference guide. Any future protocol action requests can be completed through the WVU+kc system. 


\section{Appendix H: Birth Trauma Resources}

If you would like additional resources for learning more about birth trauma, the following is a list of internet resources which may be helpful to you:

http://www.solaceformothers.org

http://www.tabs.org.nz/

http://www.birthtraumaassociation.org.uk/

http://www.sheilakitzinger.com/BirthCrisis.htm

http://www.ican-online.org/

https://www.pennysimkin.com/

http://healmyptsd.com/ 


\section{Student:}

Teresa B. Stire, MA

Date

Committee Chair:

James Bartee, PhD

Date

Committee Members:

Sarita Bennett, DO

Date

Reagan Curtis, $\mathrm{PhD}$

Date

Jeffrey Daniels, PhD

Date

Christine Schimmel, EdD

Date 